\title{
Can machines think? Inteligencia Artificial y Derecho de Daños ${ }^{1}$ \\ Can machines think? Artificial Intelligence and torts
}

\author{
José Carlos Hernández ZuluaGA²
}

\section{RESUMEN}

El presente artículo tiene como objetivo relacionar las características de la Inteligencia Artificial (IA) y reconocer su influencia en el derecho de daños. Se determinó que esta tecnología emergente dificulta la configuración de los elementos de la responsabilidad bajo las reglas tradicionales por sus rasgos disruptivos.

Para cumplir este propósito se tuvieron en cuenta recientes reportes de los principales grupos de estudio y autores que a nivel mundial se dedican al estudio de la influencia de las nuevas tecnologías en el derecho de la responsabilidad. Para el rastreo bibliográfico y el manejo documental se consultaron bases de datos, revistas indexadas y sitios web dedicados al tema de estudio.

Al concluir el escrito se pudo establecer que la IA ejerce gran influjo en la atribución de la responsabilidad a partir de la dificultad de definir el causante del daño, el complejo ecosistema digital en que actúa, la autonomía e imprevisibilidad derivada de su naturaleza algorítmica.

1 Fecha de recepción: 25 de marzo de 2020. Fecha de aceptación: 26 de junio de 2020 Para citar el artículo: Hernández J. "Can machines think? Inteligencia artificial y derecho de daños". Revist@ E-Mercatoria,vol.19,n.o 1, enero-junio, 2020.

DOI: https://doi.org/10.18601/16923960.v19n1.01

2 Máster en Derecho de Daños de la Universidad de Girona y Magíster en Derecho Procesal de la Universidad de Medellín. Especialista en Derecho Procesal Civil y Derecho de los Negocios de la Universidad Externado de Colombia. Secretario activo y miembro de listas de Tribunales Arbitrales de diferentes centros de arbitraje de Antioquia. Docente de tiempo completo de Derecho del Politécnico Grancolombiano Sede Medellín en donde se desempeña actualmente como investigador líder del proyecto: "Responsabilidad Civil en Contenidos y Servicios Digitales en Colombia" en cuyo desarrollo presenta el presente artículo.Colombia; jchernandezz@poligran. edu.co 
Se estableció que para compensar la víctima es necesario modular las exigencias probatorias, imponer responsabilidad objetiva prescindiendo de exigencias tradicionales como la determinación de la fuente del riesgo y reforzar deberes en la comercialización y adquisición de IA.

Palabras clave: Inteligencia Artificial ${ }_{i}$ Daños ${ }_{i}$ Responsabilidad Civil y Nuevas Tecnologías ${ }_{i}$ Responsabilidad objetiva ${ }_{i}$ Productos defectuosos ${ }_{i}$ Derecho civil, Derecho patrimonial, Derecho mercantil.

\section{ABSTRACT}

This article aims to relate the characteristics of Artificial Intelligence (AI) and its influence on liability. The features of this emerging technology make to reconsider liability under traditional rules.

To fulfill this purpose, recent reports from study groups were considered, as well as the publications of authors who worldwide are dedicated to the study of the influence of new technologies on the law of liability. For bibliographic tracking and document management, databases, indexed journals and websites dedicated to the study topic were consulted.

At the end of the article, it could be established that AI has a great influence on the allocation of liability based on the difficulty of defining the cause of the damage, the complex digital ecosystem in which it operates, the autonomy and unpredictability delivered from its algorithmic nature.

It was established that in order to compensate the victim, it is necessary to consider adaptations and amendments to the burden of proof, impose strict liability disregarding traditional requirements such as the source of the risk. Besides, reinforcing the range of duties of care including the acquisition and operation of $\mathrm{AI}$, among other findings.

Key words: Artificial Intelligence ${ }_{i}$ Strict Liability $_{i}$ New Technologies and Liability; Civil Law $_{i}$ Commercial Law ${ }_{i}$ Producer's Liability; Defective Products; Fault Liability.

\section{INTRODUCCIÓN}

La reflexión sobre las nuevas tecnologías en el derecho y sus efectos patrimoniales pareciera estar relegada a aquellos países que discuten seguros obligatorios en vehículos autónomos ${ }^{3}(\mathrm{VA})$, o la obligación de bots de identificarse

3 UE Comisión Europea, "Comisión Europea (2018). Documento de Trabajo de La Comisión Europea En Responsabilidad Por Tecnologías Digitales Emergentes. (25 de Abril) SWD (2018) 137 Final" (Bruselas, 2018), https://doi.org/10.1017/CBO9781107415324.004. 
frente a consumidores ${ }^{4}$, esto, mientras en Colombia aún se discute la relevancia de la ley de comercio electrónico de 1999.

Con o sin nuestra atención, las Tecnologías de la Información y las Comunicaciones (TIC) generan un efecto transfronterizo a toda economía, grande o pequeña. Una de sus manifestaciones más relevantes es la Inteligencia $\mathrm{Ar}$ tificial (IA) $)^{5}$. Su aplicación industrial supera barreras naturales y de mercado.

Según el Observatorio de la Economía Digital en Colombia ${ }^{6}$, nuestro país recién incursiona en el uso de la IA, apalancada tímidamente por grandes empresas ${ }^{7}$. En el entretanto, multinacionales con sede en Europa, Asia y Estados Unidos ${ }^{8}$, acuden digitalmente al mercado colombiano a ofrecer bienes y servicios inteligentes, sin límite, regulación o contención real de los efectos de su actividad, transformando la vida de consumidores y usuarios.

En su afán por fortalecer el ecosistema digital, Colombia ha querido acatar las recomendaciones de la Organización para la Cooperación y el Desarrollo Económico $(\mathrm{OCDE})^{9}$ dirigidas a robustecer la educación, infraestructura,

4 Renee Diresta, "A New Law Makes Bots Identify Themselves-That's the Problem WIRED," Wired, 2019, https://www.wired.com/story/law-makes-bots-identify-themselves/ (9 de febrero de 2020).

5 ITU, "Assessing the Economic Impact of Artificial Intelligence," ITU Trends 3, n'. 1 (2018): 5170-79, https://www.itu.int/dms_pub/itu-s/opb/gen/S-GEN-ISSUEPAPER-2018-1-PDF-E. pdf. Se reconoce la IA no como una tecnología sino como una familia que integra entre otras: "Computer visión, natural language, virtual assistants, robotic process automation, advanced machine learning" De esta manera en este escrito me referiré a ella como robot, sistema, máquina, etc. En contra Calo que distingue entre IA y Robot. Indicando que el último puede no integrar IA. "Robotics and the Lessons of Cyberlaw," California Law Review, n. ${ }^{\circ} 103$ (2015): 513-63.

6 Colombia Ministerio de las tecnologías de la información y las comunicaciones and ССв Cámara de Comercio de Bogotá, "Observatorio de Economía Digital en Colombia" (Bogotá, 2017), https://www.mintic.gov.co/portal/604/articles-61929_recurso_4.pdf.

7 El informe indica que las limitaciones se dan por precaria infraestructura, riesgo regulatorio y de implementación. Ibidem (p. 28).

8 Vida referencia que Apple, Google, Microsoft, Facebook y Amazon son las empresas que registran un mayor avance en el ejercicio de la IA, lo que puede variar por el carácter abierto de este entorno. JOSÉ VIDA, "Los retos de la regulación de la inteligencia artificial: algunas aportaciones desde la perspectiva europea," in Sociedad Digital y Derecho, ed. Tomás De la Quadra-Salcedo, 1st ed. (Barcelona: BOE, 2018), 216. Scherer expone que Google en el 2013 adquirió más de una docena de empresas de IA; IBM con su sistema Watson, Facebook tiene un laboratorio de IA y Microsoft con su proyecto Adam. "Regulating Artificial Intelligence Systems: Risks, Challenges, Competencies, and Strategies," SSRN Electronic Journal 29, n. ${ }^{\circ} 2$ (2015): 375, https://doi.org/10.2139/ ssrn.2609777.

9 Colombia Ministerio de las tecnologías de la información y las comunicaciones, "MINTIC Ya Está Implementando Las Recomendaciones de La OCDE Para La Trasformación Digital," Mintic.gov.co, 2019, https://www.mintic.gov.co/portal/inicio/Sala-de-Prensa/ Noticias/106833:MinTIC-ya-esta-implementando-las-recomendaciones-de-la-OCDEpara-la-trasformacion-digital. 
empresas y políticas de transformación digital. Muestra de ello es el reciente CONPES 3975 de 2019 que plantea una línea de acción en el impulso de la IA en Colombia y en programas que permitan cerrar la brecha tecnológica. Una de las estrategias es la creación del consejo internacional de expertos que permita un "ajuste normativo" mediante el seguimiento de políticas públicas de organismos multilaterales como el observatorio para la IA de la OCDE ${ }^{10}$.

Contrario a sus pares extranjeros, el sector privado nacional limita la expansión de la IA al advertir riesgo en su implementación ${ }^{11}$. La responsabilidad patrimonial por la producción, comercialización y uso de IA cuando se causan daños ${ }^{12}$ entraña un peligro al corazón de las finanzas de las organizaciones si no se conocen sus límites. En Colombia no existe sistema coherente ni suficiente que genere confianza a la inversión privada en productos de base tecnológica, esto, cuando la experiencia comparada demuestra que son los particulares quienes impulsan la economía digital. Elon Musk en su Máster Plan de Tesla, reconoce la responsabilidad civil como un factor trascendental en la implementación de su vehículo inteligente ${ }^{13}$.

La IA influye en la vida de todos, esto justifica revisar sus características, efectos y posible tratamiento jurídico a partir de las consecuencias patrimoniales de su implementación, lo que le permitirá a Colombia, en un estado más avanzado de su mercado digital, acoger recomendaciones en torno a este problema.

En este sentido y con el fin de conocer los rasgos decisivos de la IA, se abordará su definición teniendo en cuenta la constante comparación con el ser humano y como esto puede influir en el Derecho (1). Luego, se plantearán las principales características del sistema relacionando sus efectos en el derecho de daños (2). Finalmente se describirán propuestas de autores y grupos de estudio que abordan la delimitación y asignación del riesgo patrimonial de los daños causados en su fabricación, comercialización y uso, para derivar algunas reflexiones en torno al derecho colombiano $(3)_{i}$ a partir de allí se darán las conclusiones del ensayo.

\section{HUMANIZACIÓN DEL ROBOT \\ O INTELIGENCIA SOBREHUMANA}

Las nuevas tecnologías se encuentran en constante construcción. Lemley y Casey plantean que delimitar la IA es infructuoso. Como concepto, se remonta

10 Consejo Nacional de Política Económica y Social, "Documento CONPES 3975 del 8 de Noviembre de 2019" (Bogotá D.C., 2019).

11 Cf. Nota al pie 4.

12 UE Comisión Europea, "Register of Commission Expert Groups and Other Similar Entities," 2018, https://ec.europa.eu/transparency/regexpert/index.cfm?do=groupDetail. groupDetail\&groupID=3592 (9 de febrero de 2020).

13 ElOn Musk, "Master Plan, Part Deux | Tesla," Tesla.com, 2016, https://www.tesla.com/ blog/master-plan-part-deux. (23 de marzo de 2020). 
al escrito del inglés Alan Turing "Computing machinery and Intelligence (1950)"14 al sugerir: ¿Pueden las máquinas pensar? donde describe un objeto capaz de cualquier tarea siempre que fuese programada ${ }^{15}$. Las máquinas de "Turing", al trabajar conjunta y automáticamente, multiplican sus capacidades con sistemas complejos de comunicación de datos que proyectan un artefacto pensante.

Esta visión del siglo XX evolucionó hasta el término Inteligencia Artificial atribuido a un grupo de académicos convocados en Dartmouth -1956- por John McCarthy ${ }^{16}$, donde se formuló una visión computacional del lenguaje humano para resolver problemas y aprender. En síntesis, una máquina capaz de razonar. Este símil a la persona y sus aptitudes es una constante.

Buiten ${ }^{17}$ expone esta comparación afirmando que la IA razona: atribuyendo a los resultados -output-, la capacidad de ser el fundamento de posteriores programaciones -input. Calo describe la tendencia judicial de acudir a diccionarios para definir la IA ${ }^{18}$ como la simulación o imitación de la inteligencia bumana. La Real Academia de la Lengua Española la define como: "Disciplina científica que se ocupa de crear programas informáticos que ejecutan operaciones comparables a las que realiza la mente bumana, como el aprendizaje o el razonamiento lógico ${ }^{\prime \prime}$.

Esta idea humanista de la IA desborda lo conceptual e influye en lo judicial. Calo, al estudiar el sistema legal norteamericano, relacionó un robot imitador de una presentadora famosa, en el que por uso indebido de su imagen se condenó patrimonialmente al anunciante. Asimismo, por un robot de profundidad capaz de vigilar un tesoro submarino, se le otorgó tele posesión a su propietario ${ }^{20}$.

Lemley y Casey describen que la dificultad para definir la IA va de la mano con la tendencia humana a antropomorfizar ${ }^{21}$. Con todo, resalto un criterio lógico de identidad separado de cualquier concepción humanista que sirve para identificarla: la IA ejecuta autónomamente tareas imposibles de

14 Alan Turing, "Computing Machinery and Intelligence," Mind, n. 49 (1950): 433-60, https://doi.org/10.5603/ARM.a2017.0044.

15 Mark A. Lemley and BRYAN CASEY, "You Might Be a Robot," SSRN Electronic Journal, 2019, 1-55, https://doi.org/10.2139/ssrn.3327602.

16 Wikipedia, "Historia de La Inteligencia Artificial-Wikipedia, La Enciclopedia Libre," Wikipedia, 2020, https://es.wikipedia.org/wiki/Historia_de_la_inteligencia_artificial.

17 Miriam C. Buiten, "Towards Intelligent Regulation of Artificial Intelligence," European Journal of Risk Regulation 10, n. ${ }^{\circ} 1$ (2019): 41-59, https://doi.org/10.1017/err.2019.8. Definiciones que toman de diccionarios ingleses como el Merrian-Webster o el Oxford Living Dictionary.

18 RYAn CalO, "Robots in American Law," 2016, http://ssrn.com/abstract=2737598.

19 España Real Academia de la Lengua Española, "Definición de Inteligencia," Diccionario de la RAE, 2020, https://dle.rae.es/inteligencia\#2DxmhCT. (15 febrero de 2020).

20 CALO, "Robots in American Law."

21 Lemley and Casey, "You Might Be a Robot". 
cumplir por otras máquinas y tiene la habilidad de aprender. Esto último, no exclusivo del ser humano 22 .

La máquina opera con sofisticada arquitectura algorítmica ${ }^{23}$ nutrida de datos que: prioriza, clasifica, asocia y filtra información. Está regularmente diseñada para aprender con nueva información, al perfilar reglas y modelos de decisión. Esta modalidad es conocida como Macbine Learning (ML) ${ }^{24}$.

En un estado más avanzado, opera con redes neurales artificiales creadas a partir de fórmulas matemáticas ${ }^{25}$ para: "resolver problemas que requieren de razonamiento inferencial, toma de decisiones ... variando grados de autonomía, inteligencia y habilidad dinámica para resolver problemas ${ }^{\prime 26}$. Este modelo es conocido como Deep Neural Learning (DNL) ${ }^{27}$.

Sea cual fuere su consideración técnica, es su utilidad la que perfila la ia como rudimento del verdadero mercado digital: el que ha surgido con tecnología de segunda generación, que desborda las comunicaciones, los simples mensajes de datos y en el que la información dinamiza la economía. Su aplicación en el transporte ${ }^{28}$, la agricultura ${ }^{29}, \operatorname{los}_{\text {servicios }}{ }^{30}$, la publicidad ${ }^{31}$, la

22 BURTON et al sugieren atribuir responsabilidad con fundamento en el hecho de las cosas animadas, ie. tomar su autonomía característica. Simon Burton et al., "Mind the Gaps: Assuring the Safety of Autonomous Systems from an Engineering, Ethical, and Legal Perspective", Artificial Intelligence 279 (2020), https://doi.org/10.1016/j.artint.2019.103201.

23 Teresa Rodriguez de las Heras, "Legal Challenges of Artificial Intelligence: Modelling the Disruptive Features of Emerging Technologies and Assessing Their Possible Legal Impact", Uniform Law Review 24, n. ${ }^{\circ}$ (2019): 302-14. Como definición de algoritmo plantea la Profesora Rodríguez de las Heras: "una secuencia finita de instrucciones, reglas o acciones para resolver un problema". (p. 305)

24 El ML comprende funciones con auto aprendizaje. De un producto-output-, el sistema es capaz de entrenar los datos recibidos como estándares para nuevos procedimientos, eg. Virus detectado permite a la IA evadirlo posteriormente.

25 BUITEN, "Towards Intelligent Regulation of Artificial Intelligence".

26 YAVAR BATHAEE, "The Artificial Intelligence Black Box and the Failure of Intent and Causation", Harvard Journal of Law \& Technology 31, n. ${ }^{\circ} 2$ (2018): 898, https://www.theverge.com/.

27 El concepto de ML se atribuye también a Geoffrey Hinton que lo define como: "nuevas arquitecturas de redes neuronales con mayor capacidad de aprendizaje". José Vida, "Los retos de la regulación de la inteligencia artificial: algunas aportaciones desde la perspectiva europea", in Sociedad Digital y Derecho, ed. Tomás De la Quadra-Salcedo, 1. ${ }^{\text {}}$ ed. (Barcelona: boe, 2018), 206.

28 Joshie NAveEn, "How AI Can Transform The Transportation Industry", Forbes, 2019 https://www.forbes.com/sites/cognitiveworld/2019/07/26/how-ai-can-transform-thetransportation-industry/\#2eb20ce34964.(23 de febrero de 2020). Uno de los sectores con mayor impacto es el del transporte: Movilizar personas y cosas con drones, controlar vehículos y planear movilidad.

29 Ver nota al pie n. ${ }^{\circ} 54$ sobre agribots.

30 Pueden consultarse los múltiples servicios en IA ofrecidos por la compañía Amazon Web Services (AWS) y su competidor Microsoft Azure.

31 Juan Carlos Galindo, "Así Se Hizo El Primer Spot de Publicidad Creado Con Inteligencia Artificial," muyinteresante.es, accessed February 23, 2020, https://www. 
$\operatorname{salud}^{32}$, la seguridad ${ }^{33}$, la política ${ }^{34}$, la educación ${ }^{35}$, la industriaa ${ }^{36}$ y la vida en genera ${ }^{37}$ permite: "la transformación de las sociedades y la digitalización de nuestras economías ${ }^{1 / 38}$. De acuerdo con Rodríguez de las Heras, la celeridad, efectividad, simplicidad, disminución de costos de transacción y masificación de bienes y servicios son méritos no replicables por otros productos ${ }^{39}$. Su efecto expansivo no solo desarrolla productos sino su entorno. Así un vehículo inteligente irradia toda su operación: requiere autopistas y gasolineras inteligentes, seguros especiales o talleres independientes ${ }^{40}$.

Esa explosión digital inteligente tomó por sorpresa el mercado, con características que se reconocen disruptivas: ie. que moldea reglas, modelos y principios tradicionales del derecho.

\section{RASGOS DE LA IA: EFECTOS PARA LA RESPONSABILIDAD CIVIL}

La regulación de la IA ha suscitado el interés de actores como las Naciones Unidas ${ }^{41}$, la Unión Internacional de Telecomunicaciones ${ }^{42}$ o los EE.UU. En un

muyinteresante.es/tecnologia/inteligencia-artificial/articulo/asi-se-hizo-el-primer-spotde-publicidad-creado-con-inteligencia-artificial-461542818130. (23 de febrero de 2020).

32 Wikipedia, "Sistema Quirúrgico Da Vinci-Wikipedia, La Enciclopedia Libre", Wikipedia 2019, https://es.wikipedia.org/wiki/Sistema_quirurgico_Da_Vinci. (23 de febrero de 2020)

33 Louis Columbus, "10 Charts That Will Change Your Perspective Of AI In Security," Forbes, 2019, https://www.forbes.com/sites/louiscolumbus/2019/11/04/10-charts-thatwill-change-your-perspective-of-ai-in-security/\#311de57d68b7. (23 de febrero de 2020). U\$ 137 billones se esperaban fueran destinados a ciberseguridad en 2019, llegando a U\$ 173 Billones en 2023.

34 BBC, "5 Claves Para Entender El Escándalo de Cambridge Analytica Que Hizo Que Facebook Perdiera US $\$ 37.000$ Millones En Un Día-BBC News Mundo", BBC News, 2018, https://www.bbc.com/mundo/noticias- 43472797.

35 US News, "Best Artificial Intelligence Programs-Top Science Schools-US News Rankings", US News, 2018, https://www.usnews.com/best-graduate-schools/top-scienceschools/artificial-intelligence-rankings.

36 Business insider, "Artificial Intelligence Is Changing These 9 Industries", Business Insider, 2017, https://www.businessinsider.com/sc/artificial-intelligence-companies?IR=T.

37 Cf. TANYA BASAu, "The Robot Does the Hard Work. Can You Still Attain Enlightenment? -" MIT Technology Review, 2020, https://www.technologyreview.com/s/615267/therobot-does-the-hard-work-can-you-still-attain-enlightenment/. (23 de febrero de 2020).

38 Parlamento Unión Europea, "Política Industrial Global Europea En Materia de Inteligencia Artificial y Robótica", 12-02-2019, 2019, 2, http://www.europarl.europa.eu/doceo/ document/TA-8-2019-0081_ES.html?redirect.

39 Rodriguez de las Heras, "Legal Challenges of Artificial Intelligence: Modelling the Disruptive Features of Emerging Technologies and Assessing Their Possible Legal Impact". (p. 306). Es el caso de los asistentes personales, los motores de búsqueda, de reconocimiento facial, el tráfico de datos, los bots al servicio del Fintech, los traductores en línea y demás productos que en otras condiciones resultarían muy costoso desarrollar.

40 LEMLEY and CASEY, "You Might Be a Robot".

41 Por medio de su Instituto de Investigación Interregional de Crimen y Justicia (UNICRI), 
reciente reporte el Congreso dejó en evidencia la tendencia mundial de los países a diseñar estrategias digitales para ser líderes en su implementación ${ }^{43}$.

Sin perjuicio de otras aproximaciones y para el objeto de este artículo, la Unión Europea (UE), a través del Grupo de Expertos en Nuevas Tecnologías y Responsabilidad Civil (GENTRC) ${ }^{44}$, relacionó los efectos de las Tecnologías emergentes en el ámbito del derecho patrimonial por daños, reporte que servirá de base para analizar aquí los efectos de la IA en el derecho de daños ${ }^{45}$.

El grupo propone siete características de la IA con influencia en los daños: Complejidad, opacidad, autonomía, vulnerabilidad, predictibilidad, data-estructura y modificabilidad ${ }^{46}$. Este informe pretende ser reconocido como guía en el marco de la estrategia europea del Mercado Único Digital $(\mathrm{MUD})^{47}$ y seguramente servirá de parámetro para proyectar políticas en el caso colombiano ${ }^{48}$.

A continuación, describo las más relevantes partiendo de las relaciones funcionales y conceptuales existentes entre ellas. Primero, valoraré los efectos de la complejidad y opacidad considerando su afiliación a la modificabilidad ${ }^{49}$

describe la IA parte de los Objetivos de Desarrollo Sostenible (ODS), con enfoque en prevención y policía criminal junto a socios como INTERPOL.UNICRI, "Artificial Intelligence and Robotics", accessed March 16, 2020, http://www.unicri.it/topics/ai_robotics/. (16 de marzo de 2020).

42 (ITU) Agencia especializada de las Naciones Unidas para el estudio de las tecnologías de la información y las telecomunicaciones (TIC). International Telecomunication Union, "ITU: Committed to Connecting the World", 2019, https://www.itu.int/en/Pages/default. aspx. (17 de marzo de 2020)

43 American Congress, "Regulation of Artificial Intelligence in Selected Jurisdictions", 2019, http://www.law.gov. Este reporte describe el precario desarrollo mundial de políticas regulatorias enfocadas mayormente en vehículos autónomos. Canadá, Francia, Corea del Sur o Portugal trabajan en ciertas aplicaciones sectoriales de la IA sin un enfoque sistémico.

44 UE Comisión Europea, "Commission Staff Working Document. Liability for Emerging Digital Technologies Accompanying the Document Communication from the Commission to the European Parliament, the European Council, the Council, the European Economic and Social Committee and the Co", 2018, https://eur-lex.europa.eu/legalcontent/EN/TXT/PDF/? uri=CELEX:52018SC0137\& from=en.

45 Para consultar la lista de los integrantes, puede consultarse: https://ec.europa.eu/transparency/regexpert/index.cfm?do=groupDetail.groupDetail\&groupID $=3592$

46 Expert Group on Liability and New Technologies, "Liability for Artificial Intelligence Report from the Expert Group on Liability and New Technologies-New Technologies Formation," 2019, https://doi.org/10.2838/25362.(p.32).

47 Comisión Europea, "Una Agenda Digital Para Europa," 2010.

48 Javier Tamayo, Responsabilidad Por Productos Defectuosos, Primera (Bogotá D.C.: Legis, 2016). Plantea que esto sucedió, además, con la Ley 1480 de 2011 como adaptación de la legislación europea y norteamericana de consumo, especialmente la Directiva 85/374/ CE sobre productos defectuosos.

49 Entendida como la consecuencia de ser un sistema abierto -openness-a múltiples fuentes datos en el cual pueden concurrir diferentes actores y que relaciono más con la complejidad externa del sistema. 
y a la estructura de datos ${ }^{50}$ como características calificadas independientes (2.1). Luego, abordaré su predictibilidad y autonomía (2.2). En cada punto conecto reflexiones propias y ajenas.

\subsection{Perplejidad: Complejos sistemas de entender}

\section{a) Complejidad y Opacidad}

Los productos con IA se diferencian de otros en la compleja interacción de elementos internos y externos necesarios para su funcionamiento ${ }^{51}$. La interdependencia entre dispositivos tangibles, aplicaciones, datos, servicios sobre datos y conectividad propias de su entorno digital, concatenan acciones ajenas a la comprensión humana ${ }^{52}$. Su trabajo interno es misterioso, indescifrable.

Esa ininteligibilidad emana de los datos que en trillones le aporta el ecosistema digital -Big data- que, sumado a los miles de propiedades de cada elemento, integra una telaraña de variables que la hace técnicamente indescifrable $^{53}$. Si además la IA internaliza y asigna arbitrariamente un valor a cada variable para decidir, la confusión se potencializa. En el caso del DNL, la IA opera además mediante: "neuronas interconectadas que son usadas para progresivamente encontrar patrones o hacer conexiones lógicas entre datos ${ }^{\prime \prime 54}$.

A raíz de su estructura y función por datos ${ }^{55}$, la IA obra en un ecosistema de información integrado por el diseñador, programador, terceros y usuarios. Todos ejercen una injerencia en el desempeño de la IA. La máquina: recibe, procesa, categoriza y utiliza estos agentes y otros productos que también cumplen esa función ${ }^{56}$. Toda la información es determinante para el output.

50 O Data driveness según la cual la IA está sometida a datos que pueden estar sesgados, sensores averiados o con comunicaciones defectuosas que afectan el sistema. Esto, considero se trata más de un efecto de la vulnerabilidad del sistema derivado de su opacidad y consecuente desconocimiento.

51 Rodriguez de las Heras, "Legal Challenges of Artificial Intelligence: Modelling the Disruptive Features of Emerging Technologies and Assessing Their Possible Legal Impact", 308.

52 Comisión Europea, "Comisión Europea (2018). Documento de Trabajo de La Comisión Europea En Responsabilidad Por Tecnologías Digitales Emergentes. (25 de Abril) SWD (2018) 137 Final".

53 Jenna Burrell, "How the Machine 'Thinks': Understanding Opacity in Machine Learning Algorithms", Big Data and Society 3, n. ${ }^{\circ}$ (2016): 1-12, https://doi. org/10.1177/2053951715622512.

54 YaVAR BathaEe, "The Artificial Intelligence Black Box and the Failure of Intent and Causation", 902.

55 Aquí podría integrarse el elemento Data-estructura que el grupo de expertos relaciona. La complejidad de la IA surge de los algoritmos que es en todo caso información o datos.

56 West Dean, "Farming-Using Artificial Intelligence, Agricultural Robots Are on the Rise", The Economist, 2020, https://www.economist.com/science-and-technology/2020/02/06/ 
Esto la hace vulnerable, modificable a partir de ataques o programa maligno que puede afectar sus funciones y causar daños.

Esta multiplicidad de actores, funciones y sistemas fuera de control generan problemas. Basta recordar el caso del robot Tay de Microsoft creado para interactuar por Twitter y desconectado luego de un día ${ }^{57}$. Por la información contaminada en la interacción con usuarios, manifestó agrado por Hitler, negó la existencia del holocausto y de paso dejó estupefactos a sus fabricantes ${ }^{58}$.

Otra circunstancia tratada como característica independiente pero que parece solo un efecto del complejo ecosistema digital es su opacidad. Su enigmático desempeño ${ }^{59}$, la relevancia de cada dato, las innumerables variables, la borrosa imputación por las complejas interacciones del sistema y sus difusos modelos decisionales, hace vidriosa la causa ${ }^{60}$ de un daño ${ }^{61}$. Esto es conocido como The black box effect.

Según este concepto, juzgar el modelo decisional y predecir el proceso interno cuando no se entiende el producto es pretensioso. Si la opacidad es fuerte, las condiciones del procesamiento de los datos, su influencia en el resultado y el ranking de las variables son inexpugnables, aun, frente a un proceso de ingeniería inversa ${ }^{62-63}$.

using-artificial-intelligence-agricultural-robots-are-on-the-rise. (15 febrero 2020). Relaciona el caso de tres agribots: Dick, Tom y Harry. Tom escanea el cultivo con cámaras y al detectar maleza Dick actúa. Harry siembra y aplica fertilizantes de forma controlada. Esto disminuye químicos hasta en un $90 \%$, agiliza los procesos y automatiza la siembra y recolección.

57 LEMLEY and CASEY, "You Might Be a Robot".

58 ввC, "Tay, La Robot Racista y Xenófoba de Microsoft-BвC News Mundo", вBC, 2016, https://www.bbc.com/mundo/noticias/2016/03/160325_tecnologia_microsoft_tay_ bot_adolescente_inteligencia_artificial_racista_xenofoba_lb.

59 BвC Mundo Tecnología, "Google pide perdón por confundir a una pareja negra con gorilas", BBC, 2015, https://www.bbc.com/mundo/noticias/2015/07/150702_tecnologia_google_perdon_confundir_afroamericanos_gorilas_lv. (16 de febrero de 2020). Un sistema de reconocimiento de fotografías de Google confundió una pareja de norteamericanos con gorilas. Esto fue descrito por un funcionario de la compañía como: "el primero de una larga lista de errores que hubiese querido evitar".

60 The American Law Institute, "Restatement of the Law Third. Torts. Liability for Physical and Emotional Harm" (Philadelphia, 2005). (348). Según el Restatement Third, para determinar la causa necesaria de un daño, se revisan los eventos que configuran un resultado. De esta cadena causal se señalan aquellos que, si se "extraen", desvanecen el evento. Esto es conocido en el Derecho anglosajón como el but for o sine qua non test.

61 Rodriguez DE LAS Heras, "Legal Challenges of Artificial Intelligence: Modelling the Disruptive Features of Emerging Technologies and Assessing Their Possible Legal Impact", 309.

62 Yavar Bathaee, "The Artificial Intelligence Black Box and the Failure of Intent and Causation".

63 El proceso de ingeniería inversa hace relación a la técnica de descubrir los principios tecnológicos de un producto mediante la deconstrucción del objeto. Rafael Marín, 
Burrel señala que el hermetismo del sistema emana de: a) el lenguaje utilizado en su programación y sintaxis: eg. Python, b) El entendimiento del algoritmo, ie. La máquina no atiende a la lógica humana: eg. vehículo Tesla colisiona con tráiler de camión en giro de noventa grados ${ }^{64} \mathrm{y}_{i}$ c) del control corporativo ${ }^{65}$, que hace opaco el sistema al resguardo de la propiedad intelectual con fines empresariales ${ }^{66}: \mathrm{eg}$. aprendizaje adversarial para detectar spam, scam o fraudes.

Por su estructura en datos, la opacidad puede disminuir al aplicar fórmulas que tiendan a reportar la información generada en la interacción digital. Esto plantea un reto para apurar las condiciones de producción de bienes y servicios digitales que efectivicen esta tarea y a la vez, respeten derechos fundamentales.

\section{b. Influencia de la opacidad y complejidad en la atribución de daños patrimoniales}

De estas características afloran efectos con situaciones jurídicas patrimoniales novedosas sobre las que vale la pena reflexionar:

1. La imputación de responsabilidad implica individualizar el agente del daño ${ }^{67}$ y según se explicó, el hermético y complejo sistema de la IA entorpece este proceso. Si se opta por un sistema de responsabilidad objetiva, la víctima encontrará un régimen con diferentes desafíos probatorios como el del defecto del producto. Si se acude a un régimen de culpa probada, habrá de probar la negligencia del productor u operador en un sistema sellado o con múltiples actores. Incluso el hallado responsable al pagar afrontará las mismas condiciones frente a quien contractual o extracontractualmente tenga derecho a reclamar. En este sentido si un productor pretende probar que el adquirente le ha dado un mal uso al producto, encontrará barreras tecnológicas que eliminan de facto este tipo de eximentes.

"Ingeniería Inversa: Herramientas a Utilizar Para Llevarla a Cabo", accessed March 23, 2020, https://revistadigital.inesem.es/informatica-y-tics/ingenieria-inversa/.

64 Dominic RusHe, "Tesla Driver Who Died in 'autopilot' Crash Was Playing on Phone, Inquiry Finds I Technology I", The Guardian, 2020, https://www.theguardian.com/ technology/2020/feb/25/tesla-driver-autopilot-crash.

65 En clave del juicio por responsabilidad, preocupa la validez y prueba de esta opacidad intencional que sirva para evadir normas o realizar prácticas antijurídicas y que permita rehuir el efecto patrimonial de un daño por su responsable.

66 Burrell, "How the Machine 'Thinks': Understanding Opacity in Machine Learning Algorithms".

67 Ricardo De Ángel Yáguez, "Actuación dañosa de los grupos", Revista Jurídica de Cataluña, n. ${ }^{\circ} 4$ (1997): 63-91. Se exceptúa con bastante polémica en el derecho español la aplicación de la responsabilidad de una persona indeterminada de un grupo determinado en aplicación de la doctrina pro damnatio. 
Como se advierte, el disperso escenario fáctico y jurídico propiciado por los rasgos característicos de la tecnología emergente promete retos a todas las partes involucradas. Si por ejemplo una víctima demanda al operador de un dron defectuoso por un daño en su propiedad y éste paga, la repetición al productor dependerá de la información recuperada. Si en otro caso un robot difama a un enemigo de su propietario, para probar el ilícito de este último hace falta más que conocer al demandado. A mi parecer, existirán casos en que la asimetría que justifica la protección del consumidor no existe, con el posible efecto de tener que reexaminar el principio pro consumatore ${ }^{68}$.

Para alivianar la carga tecnológica, se plantea con polémica la e-personality como opción jurídica para imputar responsabilidad cuando no sea posible asignar el deber de indemnizar. A pesar de lo creativa, esta idea se repele por las dificultades prácticas y jurídicas que conlleva ${ }^{69}$. Se buscan políticas indemnizatorias acordes a las características de la IA que no generen más enredos. Esto no parece sencillo.

Si se impone al productor una responsabilidad objetiva subsiste el injusto: éste podría ignorar quién o que determinó el resultado, además que la atribución sin culpa se justifica como incentivo para evitar al límite la causación del daño ${ }^{70}$. Si desaparece el estímulo, lo hará también parte del argumento para sostenerla. El posible efecto de esa responsabilidad estricta: ralentizar la innovación y aumentar costos en la producción de tecnología.

Adicionalmente la responsabilidad objetiva impone que el propietario indemnice los daños causados por sus cosas, pero si el fabricante sigue controlando

68 Una de las principales justificaciones del derecho de consumo es la desigualdad de las partes. "Es constante la afirmación de la posición materialmente desigual (la asimetría) en el tráfico de los consumidores frente a los empresarios o profesionales. La prevalencia constitucional de los intereses de los consumidores sólo puede lograrse, desde esta perspectiva, a través de una disciplina especial". JOSÉ RAMÓN GARCía VICENTE, "La Contratación Con Consumidores", in Tratado de Contratos, Tomo II. 2. a ed., ed. Rodrigo Bercovitz, 1st ed. (Valencia: Tirant lo Blanch, 2013), 1637.

69 Férrea oposición se da a esta idea bajo consideraciones éticas y económicas como la de posible fraude, la ineficacia de un verdadero patrimonio autónomo o la asignación de derechos humanos a una máquina. Para profundizar puede consultarse la carta abierta de un grupo de académicos publicada en: Robotics Openletter, "Robotics Openletter I Open Letter to the European Commission", 2017, http://www.robotics-openletter. eu/. Ryan AввотT, "The Artificial Inventor Project", WiPO Magazine, 2019, https:// www.wipo.int/wipo_magazine/en/2019/06/article_0002.html. (12 de marzo de 2020). En otro caso la oficina europea de patentes negó el registro de dos inventos a nombre de Dabus AI, un sistema inteligente, aduciendo la solicitud por una máquina y no una persona.

70 "La obligación de compensar pérdidas injustas se impone al agente dañador a fin de que cuente con los incentivos necesarios para adoptar medidas precautorias óptimas o restringir su actividad a los daños eficientes". Diego PapaYAnnis, "Veinte Años de Riesgos y Daños. Una Propuesta Arriesgada y Poco Dañosa", en Derecho de Daños, Principios Morales y Justicia Social, ed. Diego Papayannis, 1st ed. (Barcelona: Marcial Pons, 2013), 20. 
el producto después de su entrega, situación por demás frecuente en el tráfico mercantil moderno -fenómeno denominado: "la digitalización de las ventas" por el European Law Institute ${ }^{71}-$, la imposición exclusiva al usuario no parece equitativa ni lógica.

De otro lado ${ }^{72}$, la responsabilidad por productos defectuosos ${ }^{73}$ exime al operador de daños derivados del bien si no pudo evitar el resultado, cuando el Marco Común de Referencia (DCFR) ${ }^{74}$ adopta la teoría del control sobre el dependiente para asignarle responsabilidad.

Por consiguiente, cuando se emplea una persona, el contratante responde objetivamente del hecho imputable a sus dependientes ${ }^{75}$. Si esa persona se sustituye por IA y esta causa daño, el usuario puede alegar que le era imprevisible, lo que no sucede con auxiliares humanos aun si el riesgo en este caso fuera mayor.

En otros casos, dada la atribución objetiva del riesgo, el gasto en IA será económicamente ineficiente. Contrario a una máquina, si un empleado causa un daño, su empleador será juzgado con culpa probada. Esto genera incentivos de contratación humana para minimizar riesgos de operación, por lo menos, mientras la IA se negocie como un producto cualquiera ${ }^{76}$. Este costo se traslada al usuario final o a la adquisición de un seguro, encareciendo el acceso a productos de base tecnológica en déficit del progreso, la ciencia y la innovación.

Si por el contrario se establece una responsabilidad basada en culpa, los problemas probatorios de identificación van a la víctima: recuerde las múltiples fuentes del ecosistema digital ${ }^{77}$ y la complejidad técnica que entraña. La

71 European Law Institute, "Statement of the European Law Institute On the European Commission's Proposed Directive on the Supply of Digital Content to Consumers", 2015.

72 Cf. Numeral 2.2. sobre autonomía e imprevisibilidad.

73 De acuerdo con Tamayo, la teoría del riesgo debe distinguirse de la responsabilidad objetiva en tanto ambas descartan la culpa, pero aquella admite concesiones como no ser posible anticipar el riesgo que se está creando. Esto no sucede en la responsabilidad puramente objetiva. Tratado de La Responsabilidad Civil. Tomo I, 2. ${ }^{a}$ ed. (Bogotá D.C.: Legis, 2013), 822.

74 UE Study Group on a European Civil Code., "Principles, Definitions and Model Rules of European Private Law", 2007.

75 Responsabilidad vicaria o por el hecho de los otros. Se distingue según su fuente contractual o extracontractual. En el primer caso se responde objetivamente, en el segundo de acuerdo con la culpa o actividad peligrosa imputable al dependiente. En países como Alemania el daño causado por otros es la excepción y debe tener una justificación. J SPIER, Unification of Tort Law: Liability for Damages Caused by Others, ed. European Center of Tort and Insurance Law (ECTIL), 1st ed. (Vienna: Kluwer Law, 2003), 105.

76 Ryan ABвotT, "The Reasonable Computer: Disrupting the Paradigm of Tort Liability", George Washington Law Review 86, n. ${ }^{\circ}$ (2018): 1-45, https://doi.org/10.2139/ssrn.2877380.

77 Es el caso de los vehículos autónomos es notorio el progreso en investigación y desarrollo que transforma su entorno tecnológico. Ejemplo de ello es el modelo R2 de Nuro 
víctima puede verse tentada a no reclamar ya que debe probar que el empresario ha quebrantado un deber, lo que puede suponer interpretar un lenguaje cifrado o acceder a propiedad intelectual. De no demostrarse, sigue siendo responsable solo quien pueda considerar los riesgos técnicos y axiológicos del efecto dañoso ex ante ${ }^{78}$.

Abbott defiende esta teoría incluso para juzgar actuaciones de las máquinas. Expresa que cuando se produzca mayor seguridad con IA que con humanos, surge un nuevo nivel de exigencia: The reasonable computer. Esta máquina se convierte en el parámetro de diligencia ${ }^{79}$. Así, la omisión imprudente en su empleo por el nivel de seguridad que ofrezca comparado con un humano genera responsabilidad para el operador. En este supuesto la persona es insuficiente, la máquina puede hacerlo mejor. Esto supone una fe ciega en algo que no se entiende.

2. En clave de la responsabilidad por productos defectuosos, es opacidad es determinante para el consumidor que carga con la prueba del defecto del bien. El defecto parte de la transgresión de una norma o de una razonable expectativa de seguridad que para la IA aún no existe. Para el afectado, la prueba de ese defecto se desvanece en directa proporción al hermetismo del sistema. En el año 2017, Facebook desconectó un chatbot que creó su propio lenguaje: la compañía admitió ser incapaz de interpretarla ${ }^{80}$.

Ahora bien, con la prueba del defecto del producto el demandante actualmente hace esfuerzos ingentes del quebranto de la norma o de la razonable expectativa de seguridad, que podría esperarse en estos casos. De no existir la norma que parametrice esa seguridad, a la difusa IA ha de sumársele el conflicto de determinar que era seguro para la víctima en un entorno algorítmico. Lo anterior sin contar con que el productor es libre de imponer condiciones contractuales de operación, mantenimiento o control. Sin estándares de seguridad el producto, estructurado sobre fórmulas matemáticas exactas, ha de juzgarse según la intuitiva creencia de un juez inexperto y lo que creyó seguro. ¡Nuevamente un acto de fe!

sin humanos, que le ha permitido exenciones regulatorias como la de no incluir vidrios laterales.Alex Davies, "This Vehicle Has No Side-View Mirrors-and It's Legal", Wired, 2020, https://www.wired.com/story/vehicle-no-side-view-mirrors-legal/. (22 de febrero de 2020).

78 BurTON et al., "Mind the Gaps: Assuring the Safety of Autonomous Systems from an Engineering, Ethical, and Legal Perspective". Los autores plantean la teoría del equilibrio reflectivo (Jhon Rawls) como proyección técnica de los sistemas desde el diseño -semántico- hasta el efecto moral que tiene, estableciendo barreras a la responsabilidad a partir de estos criterios. Así, se juzga ex ante el posible resultado. Milenio, 2018, https://www.milenio.com/estilo/como-la-ia-de-facebook-pudo-crearsu-propio-lenguaje. 
Para mitigar estos efectos, la claridad de la IA es prioridad legislativa. The Economist expresa que la forma de "abrir la caja" es equiparando el lenguaje humano y el digital mediante software de pares que explique su proceso decisional, ie. La máquina analiza la máquina ${ }^{81}$. Burrel recomienda socializar el lenguaje digital algorítmico o auditar la programación para revisar los procesos de control en cada etapa de la IA ${ }^{82}$. Estas etapas que propone dividirlas en tres fases: datos, seguimiento de resultados y modelos de decisión. Evaluando cada etapa puede entenderse su operación ${ }^{83}$.

Si los datos son el fundamento de la IA, la vulnerabilidad a consecuencia de las fallas provocadas por su diseño debe asumirlas el empresario, quien frente a un daño en el que no sea posible probar el defecto, debe reconducir los indicios a su favor. Asumo en contra de la consideración del GENTRC que la inversión de la carga probatoria sea la salida procesal para salir del conflicto. Esto puede resultar perjudicial de los intereses del progreso científico por lo que un tratamiento a partir de indicios parece ser más equitativo. No me refiero a eliminar la inversión frente a cualquier defecto, solo por afectaciones digitales a causa de la vulnerabilidad del robot.

Sin embargo, la opacidad característica del sistema no es la única relevante en el contex to de la IA. Actualmente, uno de los principales retos regulatorios son los sistemas creados por sujetos aislados entre sí, sin contacto directo, incluso extraños, que con intención o sin proponérselo crean a partir de open source software, productos que luego son comercializados. La forma de operar incluye diferentes jurisdicciones, sin infraestructura visible y con independencia entre unos y otros, donde los componentes del producto llegan de diferentes proveedores, ignorantes de la finalidad concurrente ${ }^{84}$.

En este caso la causalidad es tan difusa que la imposición de responsabilidad a un programador cuya creación ha sido en tal nivel modificada hará dudar hasta el juez más exegético.

3. Además del problema de la causalidad fáctica y su complejidad técnica, la imputación objetiva ${ }^{85}$ del daño supone otro asunto complejo de analizar.

81 Stephanie Scholz, "AI in Society-For Artificial Intelligence to Thrive, It Must Explain Itself", The Economist, 2018, https://www.economist.com/science-and-techno$\log / 2018 / 02 / 15 /$ for-artificial-intelligence-to-thrive-it-must-explain-itself.

82 Burrell, "How the Machine 'Thinks': Understanding Opacity in Machine Learning Algorithms".

83 BUITEN, "Towards Intelligent Regulation of Artificial Intelligence."

84 SCHERER, "Regulating Artificial Intelligence Systems: Risks, Challenges, Competencies, and Strategies".

85 El profesor Fernando Pantaleón puso de presente desde 1990 el concepto de imputación objetiva en el derecho español, diferenciándolo de la mera condicio sine qua non, expresando: "Por ello puede afirmarse que la existencia o no de una relación de causalidad es una cuestión de hecho, libre de valoraciones específicamente normativas. Por el contrario, el problema de la imputación objetiva -la función de cuyos criterios es evitar que sean 
Considero que algunas causales de imputación objetiva del daño resultarán imposibles de demostrar por el doliente. Es el caso de la prohibición de regreso cuando el demandado intente aclarar, mediante códigos y programaciones indescifrables, que no era garante del hecho generador del perjuicio. En estos eventos, a más de una responsabilidad objetiva existe presunción de causalidad que puede llevar a una presunción de responsabilidad. Esta situación se replica en otras situaciones de imputación objetiva como el que emana de la provocación ${ }^{86}$ por uso inadecuado de la víctima.

Lo ideal sería que el análisis ex post de la causa permita que todas las partes obtengan información relevante. El productor se supone tiene acceso al modus operandi del robot y sus datos, pero esto no es siempre cierto. Como se verá, el GENTRC para justificar la asignación del nexo de causalidad, reversa a la teoría de la causalidad adecuada planteada por $\operatorname{Trager}^{87}$, donde la imputación deriva de un juicio probabilístico de que el ilícito pueda anticiparse por un observador experto, en este caso, el fabricante.

\subsection{LA MÁQUINA DE TURING: ¿CAN MACHINES THINK?}

\section{a. Imprevisibilidad y autonomía}

Ya se vio como las tecnologías de segunda generación ${ }^{88}$ presuponen una intrincada estructura y con ello, la tercera de sus características: imprevisibilidad. La IA propaga: "... sistemas diseñados no solo para responder a un estímulo predeterminado, sino para identificar y clasificar otros, vinculándolos a datos para los cuales no ha sido programado...A mayor cantidad de estímulos externos, mayor imprecisión del impacto de su operación" ${ }^{\prime \prime 9}$.

puestas a cargo del responsable absolutamente todas las consecuencias de las que su conducta es la causa- es una cuestión claramente jurídica, un problema de valoración a resolver con las pautas, más o menos precisas, ofrecidas por el sistema normativo de responsabilidad". Fernando PANTALEÓn, "Causalidad e Imputación Objetiva: Criterios de Imputación"., in Centenario Del Código Civil (1889-1989), Tomo II, ed. Editorial Centro de Estudios Ramón Areces (Madrid: Centro de estudios Ramón Areces, 1990), 1561-92.

86 Pantaleón.

87 Luis DíEZ-PICAZO, Fundamentos de Derecho Civil Patrimonial V. La Responsabilidad Civil Extracontractual., 1st ed. (Navarra: Civitas, 2011), 364.

88 La normativa efecto del principio de equivalencia funcional ha permitido la comunicación, formación y conclusión de negocios digitales a partir de la infraestructura del internet, los pagos electrónicos, la comunicación digital y en general el comercio electrónico. Esta primera etapa digital ha quedado relegada por una segunda ola de producción tecnológica del Internet de las Cosas (IoT), la tecnología Blockchain y la IA. Teresa Rodríguez de Las Heras, "Digital Technology-Based Solutions for Enhanced Effectiveness of Secured Transactions Law: The Road to Perfection?," Law and Contemporary Problems 81, n. ${ }^{\circ} 1$ (2018): 21-44.

89 Expert Group on Liability and New Technologies, "Liability for Artificial Intelligence 
Por la subordinación al entorno, su programación y su naturaleza independiente, la IA procesa información que la conduce a resultados inesperados. El modelo decisional y la semántica de programación son extraños aun para los fabricantes, por lo que, al resignar el control humano en pro del resultado, la IA cobra vida. Esto implica respuestas espontáneas posiblemente dañinas ${ }^{90}$ que pueden desviarse de la intención del productor con un problemático juicio de atribución.

La otra característica de la IA: su autonomía, frecuentemente se explica ${ }^{91}$ con referencias a ciencia ficción donde la máquina pensante elimina al hombre: como HAL ${ }^{92}$ o Skynet de The terminator ${ }^{93}$. En este argumento, la independencia del robot produce conflictos con principios y valores humanos, algo cada vez más cercano: un sistema de reconocimiento de fotografías de Google confundió dos norteamericanos con gorilas ${ }^{94}$. Pero esta soberanía no es absoluta, la IA decide a partir de algoritmos de autoaprendizaje, esto involucra siempre un acto humano (buman in command), un programador ${ }^{95}$.

Es esta intervención humana el hilo conductor entre la independencia y su imprevisibilidad. Si bien su actuación autónoma es inherente, poder preverla hace la diferencia entre imputar daño a un productor o no. En otras palabras, la independencia se relaciona con la previsibilidad en la falta de control humano en el sistema: si se anticipa se subordina. Luego, juzgo que todo daño derivado de un acto autónomo de la IA debe por regla general asumirlo el productor a raíz del provecho económico obtenido, el riesgo creado y en general, por mera justicia correctiva.

Esto admite excepciones cuando no haya deber del productor de monitorear, actualizar, evitar daños del sistema, sea desproporcionado-como en ataques digitales no imputables-o se pacten exclusiones contractuales justificadas. Sobre este punto Kowert, en contra de las conclusiones del

Report from the Expert Group on Liability and New Technologies-New Technologies Formation".

90 Jhon Lamb, "Discriminating Algorithms: 5 Times AI Showed Prejudice," NewScientist, 2018, https://www.newscientist.com/article/2166207-discriminating-algorithms5-times-ai-showed-prejudice/. (9 de marzo de 2020). Persona arrestada por confusión idiomática en facebook y tomado por terrorista.

91 Vida, "Los retos de la regulación de la inteligencia artificial: algunas aportaciones desde la perspectiva europea"; Yavar Bathaee, "The Artificial Intelligence Black Box and the Failure of Intent and Causation"; DAVID C. VLADECK, "Machines without Principals: Liability Rules and Artificial Intelligence", Washington Law Review 89, n. ${ }^{\circ} 1$ (2014): 117 50; Buiten, "Towards Intelligent Regulation of Artificial Intelligence".

92 STANley Kubrick, 2001: Una Odisea En El Espacio (USA, 1968).

93 JAMES CAMERON, The Terminator (USA, 1984).

94 Cf. Nota 48.

95 "Los retos de la regulación de la inteligencia artificial: algunas aportaciones desde la perspectiva europea." 
GENTRC, plantea que como el productor puede anticipar el uso indebido, debe responder incluso por culpa del usuario ${ }^{96}$.

\section{b. Incidencias de la Autonomía y la Imprevisibilidad en la atribución de daños patrimoniales}

1. En casos de culpa probada el propietario reclamará exención cuando la tecnología sea imprevisible. Díez Picazo fija esta predictibilidad como fundamento de la culpa ${ }^{97}$. Ya se anotó que esto lleva a conclusiones poco lógicas cuando la IA se utilice en reemplazo de actividades humanas.

2. Desde el análisis económico del derecho la asignación de deberes indemnizatorios tiene en cuenta la previsión como un criterio primordial. La fórmula del Juez Learned Hand ${ }^{98}$ expresa que las prevenciones que se omitieron (B), han de ser menores que el resultado entre la probabilidad de causación (P) y la gravedad (L) del daño.

En lesiones de bienes jurídicos importantes como la vida o la integridad personal, al analizar la falla siempre resultará que escribir unas líneas de programación más, era una prevención debida ${ }^{99}$.

3. De lado de los productos defectuosos, la previsibilidad es el soporte de la eximente por riesgo en el desarrollo. Esta se estructura en la Directiva de Productos Defectuosos ${ }^{100}$ y en el Estatuto del Consumidor colombiano ${ }^{101}$ por aquellos daños imposibles de anticipar.

De acuerdo con Tamayo, no es lo mismo un producto defectuoso que uno peligroso. Según el autor, cuando el bien puede causar un daño, pero es socialmente útil, la víctima debe asumir el riesgo si no es detectable el defecto por el estado de la técnica antes de su puesta en circulación ${ }^{102}$. Estimo su conclusión pertinente en productos tradicionales. La IA trastorna estas condiciones por el consenso sobre el riesgo de daño como constante.

96 "Liability for Artificial Intelligence Report from the Expert Group on Liability and New Technologies-New Technologies Formation," 43.

97 Díez-Picazo, Fundamentos de Derecho Civil Patrimonial V. La Responsabilidad Civil Extracontractual., 276.

98 Fórmula donde Breach es menor a Probability x Magnitude (B<PxL)

99 W. KOWERT, "The Foreseeability of Human-Artificial Intelligence Interactions", Texas Law Review 96, n. 1 (2017): pp. 181-204, http://scroll.lib.westfield.ma.edu:2090/ehost/ detail/detail?vid=3\&sid=2e 573118-5b03-4fd6-9c4e-e61699bd5225\%40sessionmgr 40 09\&bdata $=$ JnNpdGU9ZWhvc3QtbGL2ZQ\%3D\%3D\#db $=a$ ph\&AN $=126913534$.

100 UE Consejo Europeo, "Consejo Europeo (1985). Relativa a La Aproximación de Las Disposiciones Legales, Reglamentarias y Administrativas de Los Estados Miembros En Materia de Responsabilidad En Daños Causados Por Productos Defectuosos. (25 de Julio) [Directiva 85/374/CEE]. D.O:" (1985). Cf. Art. 7

101 Cf. Art. 22.

102 Responsabilidad Por Productos Defectuosos, 184. 
4. En la teoría de la causa adecuada, cuyo análisis estadístico concibe un juicio de probabilidad sobre la influencia del agente en el daño, la imputación deriva de las condiciones previstas y las: "que resultaran cognoscibles para un ideal observador experimentado"103.

De esta manera el grado de desconcierto del demandado está en directa proporción a la posibilidad de ser relevado del pago. Kowert plantea que la peligrosidad de la IA en el derecho norteamericano fundamenta su aplicación aun enfrentada a una conducta criminal. Sustenta su tesis en el ejemplo de un robot que ataca un cartero de color porque considera que va a robar a su racista propietario, el cual debe ser declarado responsable.

Si rastrear la causa lleva a definir el sujeto que controla la fuente del daño, determinarlo es un desafío o una política. Lemley y Casey plantean que la forma más efectiva de regular el control es prohibir conductas lesivas, ie. Enfocarse en la acción más que en el sujeto u objeto, lo cual supondría activar la utilización como principal fuente de daños.

\section{PROPUESTAS REGULATORIAS E INQUIETUDES DIAGNÓSTICAS}

La propuesta de regulación del GENTRC concluye inútil proyectar reglas definitivas ${ }^{104}$ para los daños causados por IA. Prefiere promover opciones con criterios de interpretación abiertos. Esta modalidad tiene inconvenientes ${ }^{105}$, principalmente por la diversidad de normas, su tradición jurídica y la interpretación que de ellas hacen sus tribunales locales. Su mérito radica en ser un modelo de unificación europeo que aborda los principales escollos regulatorios. Se presentan las ideas principales con ciertas consideraciones propias sobre sus efectos en Colombia, teniendo que posponer el análisis riguroso de sus consecuencias por razones de extensión y profundidad.

Para hacerlo se inicia con las propuestas en punto del factor de atribución, luego se abordará la causalidad $;$ y se culminará con el daño.

1. La responsabilidad objetiva se impone cuando por la creación de un riesgo o provecho obtenido, sea justo que el operador o productor asuma los

103 Fundamentos de Derecho Civil Patrimonial V. La Responsabilidad Civil Extracontractual., 365.

104 "Liability for Artificial Intelligence Report from the Expert Group on Liability and New Technologies-New Technologies Formation", 36.

105 Beale detalla dificultades de la unificación: 1. Insuficientes por las diferentes técnicas, aplicaciones e interpretaciones que pueden darse en los Estados; 2 . La intención con que se formulan debe explicarse o se pierde su función $y_{;} 3$. La diversidad de leyes locales sustancialmente diferentes son inaplicables en todos los contextos."The Role for European Contract Law", in Uniform Rules for European Contract Law? A Critical Assessment, ed. Francisco Elizalde de, 1st ed. (Oxford: Hart Publishing, 2018), 9-36. 
daños. Para ello se valora la posibilidad de lesionar bienes jurídicos importantes como la integridad personal y la propiedad, así como la utilización de la máquina en ambientes no domésticos. Por ende, un robot casero no aplica para responsabilidad objetiva, lo mismo que máquinas estacionarias.

En Colombia esta visión estaría sometida a norma expresa por no existir cláusula general de responsabilidad objetiva: el acercamiento es especial. Aquí, los riesgos creados en relaciones socialmente aceptadas producen responsabilidad por actividades peligrosas, esto es, una tipología acogida por el sentido literal del artículo 2356 C.C ${ }^{106}$. En esta interpretación se prescinde de la culpa, ie. Se aborda la conducta como cuestión de causalidad, por lo que el juez está llamado a verificar si del peligro se produjo el daño.

Ese riesgo deriva tanto de la actividad, como de la cosa inerte peligrosa. A consecuencia, el propietario o usuario, además del productor siempre garantiza los daños causados por el bien que se considere peligroso cuando esté bajo su guarda. Solo se exime por una causa extraña. Tamayo ${ }^{107}$ va más allá cuando defiende su teoría de la garantía del propietario por daños causados con sus cosas -artículo 669 C.C. En su postura, replica la vieja discusión del artículo 1384 del Código Civil francés que impone responsabilidad objetiva al guardián de la cosa.

Bajo esta lógica, los daños que cause la IA bajo los principios del Código de Bello generan responsabilidad del productor, comprador, operador, diseñador o tercero titular de derechos de propiedad intelectual si alguna guarda tiene: ya por el riesgo inherente, la actividad peligrosa realizada o su titularidad. Eso sí, podrá el injustamente demandado alegar concurrencia de actividades peligrosas para que el juez module en su favor el deber de indemnizar, lo cual sucederá luego de pagar solidariamente el daño reclamado.

2. En contraste, la imputación jurídica que presenta el GENTRC pesa sobre quien tenga mayor control. Este control es del operador ${ }^{108}$ que directa -frontend operator-o indirectamente-Backend operator-direccione el sistema. El primero por obtener un provecho inmediato, el segundo por perfilar las condiciones del producto y beneficiarse del uso del bien o sus datos. Se deja de lado la calidad de usuario, propietario, productor, empresario, etc.

106 Corte Suprema de Justicia de Colombia, "C.S.J, Sala Civil (24 de Agosto de 2009) [M.P. William Namén Vargas]" (Bogotá D.C., 2009); Corte Suprema de Justicia de Colombia, "C.S.J,Sala Civil. (Marzo 14 de 1955)[M.P.Fernando Gómez Posse] G.J. XXIX, p. 740" (Bogotá D.C., 1955).

107 Tratado de La Responsabilidad Civil. Tomo I, 840.

108 European Group on Tort Law, Principios de Derecho Europeo de La Responsabilidad Civil, Principios de Derecho Europeo de La Responsabilidad Civil. Texto y Comentario. Traducción Española a Cargo de La Red Española de Derecho Privado y Comparado REDPEC, 1. ${ }^{\text {a }}$ ed. (Navarra: Thomson Aranzadi, 2008), 153. Los PETL hablan de: "guardián (keeper) o en la persona que explota (operator) una cosa o actividad peligrosa y se dirigen, por consiguiente, a la persona: que ejerce control efectivo o que....económicamente controla la actividad". 
La calidad se fija por el control y beneficio reportado por la cosa. El operador será quien cumpla mejor con estos criterios. De existir dos o más, responderá objetivamente quien tenga mayor control. Los hermanos Mazeaud plantean que: "(...) la noción de control es más amplia que la de dirección material controlar es poder dar órdenes ${ }^{\prime \prime 109}$ lo que no ocurre en este tipo de sistemas, donde habrá de definirse legislativamente quién y por qué se debe responder. La visión del Law and economics atribuye el daño al cheapest cost avoider, concepto que termina por acoger el grupo de expertos.

Esta idea coincide con la situación actual del derecho colombiano donde la guarda deriva del control material o jurídico sobre la cosa y que, de no definirse en contrario, seguirá afectando tanto al adquirente o usuario como al vendedor o productor en perjuicio de los costos y la masificación de la IA, por lo que es plenamente replicable en nuestro ordenamiento.

3. La responsabilidad por producto defectuoso surge por lesión al consumidor, un tercero o a bienes diferentes del vendido. En el GENTRC se incluye como producto los intangibles, abandonando la tradicional definición de bien y su distinción con el servicio ${ }^{110}$. Frente a esto se argumenta que la Directiva 85/374/CEE sobre productos defectuosos ${ }^{111}$ fue redactada para bienes que en su momento cumplían la función que hoy tiene la IA. No obstante, esta fórmula, sufre de una notoria contradicción las normas que desde la Directiva 1999/44/ $\mathrm{CE}^{112}$ definen como bienes solo aquellos tangibles, criterio que coincide con la interpretación del Tribunal de Justicia de la Unión Europea (TJUE) ${ }^{113}$.

En el derecho colombiano la cuestión se agrava. A partir de la Ley 1480 de 2011 los productos son todo bien o servicio ${ }^{114}$. Pero los productos defectuosos solo son bienes muebles o inmuebles ${ }^{115}$. De allí la vidriosa posibilidad

109 Lecciones de Derecho Civil. Parte Tercera. Columen IV. Los Principales Contratos (Continuación), ed. Luis Alcalá-Zamora y Castillo, 1. ${ }^{a}$ ed. (Buenos Aires: Ediciones Jurídicas EuropaAmérica, 1974), 228

110 Luis Díez Picazo and Antonio Gullón, Sistema de Derecho Civil. Vol. II., 6. ${ }^{a}$ ed. (Madrid: Tecnos, 1992).

111 Consejo Europeo, Consejo Europeo (1985). Relativa a la aproximación de las disposiciones legales, reglamentarias y administrativas de los Estados miembros en materia de responsabilidad en daños causados por productos defectuosos. (25 de julio) [Directiva 85/374/CEE]. D.O:No. L 210/29 del 7.8.85

112 UE Parlamento y Consejo Europeo, "Parlamento y Consejo Europeo. [Mayo 25 de 1999]. Sobre Determinados Aspectos de La Venta y Las Garantías de Los Bienes de Consumo. (Directiva 1999/44/CE). D.O: L.171/12 (Julio 7/99)" (1999).

113 "Sentencia Del stjue (Gran Sala) Del 21.12.2011, Caso C-495/10 Consulta Elevada Por Conseil d'État (Francia)," 2011; "Sentencia Del STJue Del 24.3.2002, Caso C-183/00 Partes: González Sanchez vs. Medicina Asturiana," 2002.

114 Art. 5 (8), Congreso de la República de Colombia, "Congreso de Colombia. (2011). Por medio de la cual se sxpide El Estatuto Del Consumidor y se dictan otras disposiciones. [Ley 1480 de 2011] Octubre 12. D.O.48.220" (2011). (En adelante EC)

115 Ibidem, Art. 5 (17). 
de integrar los daños derivados de propiedad inmaterial sin un medio físico que proyecte la lesión. En este punto se reclama nuevamente claridad legislativa para definir el alcance de lo que es en Colombia un producto digital y si le es aplicable el régimen de productos defectuosos.

4. La obligación de seguridad del producto se mantiene aún después de la entrega al consumidor. Esto se explica por el riesgo generado, el provecho obtenido y siempre que se mantenga el control sobre actualizaciones o mejoras a la tecnología. El empresario es garante por el tiempo en que, según criterios objetivos y subjetivos de conformidad del contrato, deba asumir la seguridad de las cosas ${ }^{116}$.

En Colombia, el EC plantea dos retos para la seguridad de los productos. El primero tiene que ver con el subsistema nacional de calidad y los reglamentos técnicos aplicables y que no definen las condiciones de seguridad en que se deben comercializar bienes de base tecnológica como la IA.

La Comisión de Regulación de Telecomunicaciones ha expresado que se trata de servicios de información que se rigen por normas de competencia y de consumo ${ }^{117}$, no sometidos a autorización o régimen de vigilancia especial.

En segundo lugar, el hecho notorio y reconocido por el Gobierno nacional de la ignorancia y permisividad en este campo genera desventajas competitivas: a. Con la limitación contractual de la garantía agravada por celebración de contratos clickwrap ${ }^{118} ;$ b. La ya anacrónica Ley 1581 de $2012^{119}$ sobre protección de datos que no establece medidas óptimas como la protección por diseño o por defecto, portabilidad de datos, etc.; c. La imposibilidad práctica de reclamación efectiva a multinacionales tecnológicas ${ }^{120} \mathrm{O}_{i}$

116 UE Parlamento y Consejo Europeo, "Parlamento y Consejo Europeo. (20 de Mayo) Directiva (UE) 2019/770 Relativa a Determinados Aspectos de Los Contratos de Suministro de Contenidos y Servicios Digitales. D.O: 22 de Mayo de 2019." (2019); UE Parlamento y Consejo Europeo, "Parlamento y Consejo Europeo. (20 de Mayo). Directiva (UE) 2019/771 Relativa a Determinados Aspectos de Los Contratos de Compraventa de Bienes, Por La Que Se Modifican El Reglamento (CE) n.o 2017/2394 y La Directiva 2009/22/CE y Se Deroga La Directiva 199" (2019).

117 Colombia Comisión de Regulación de Comunicaciones, "Resumen Recomendaciones Normativas y Regulatorias Para Promocionar Los Contenidos y Aplicaciones y El Internet de Las Cosas" (Bogotá, 2016), https://www.crcom.gov.co/recursos_user/2016/ Actividades_regulatorias/PCA_IoT/Informe_6_PCA_IoT.pdf.

118 Sergio Cámara lapuente, "La Nueva Protección Del Consumidor de Contenidos Digitales Tras La Ley 3/2014, de 27 de Marzo," Revista CESCO de Derecho de Consumo, n. ${ }^{\circ} 11$ (2014): 79-167.al ordenamiento español, por medio de la Ley 3/2014, de 27 de marzo, se ha incorporado al Texto Refundido de la Ley General para la Defensa de los Consumidores y Usuarios (TR-LGDCU). Plantea la dudosa aceptación de contratos en contextos electrónicos donde el consumidor no lee las condiciones de prestación de los servicios.

119 Congreso de la República. (2012). Por la cual se dictan disposiciones generales para la protección de datos personales. [Ley 1581 de 2012]. Octubre 18. D.O: 45587

120 Cfr. Superintendencia de Industria y Comercio, "Superintendencia de Industria y 
d. El riesgo en el desarrollo legalmente reconocido para todos los casos de productos defectuosos

Sobre esta última dificultad, el grupo de expertos elimina esta eximente siempre que sea predecible un desarrollo imprevisible. En este punto, aunque estoy de acuerdo con esta eliminación, resulta polémica la determinación de esa previsibilidad que parece adscribirse a un régimen de culpa por el reproche al productor que pudo conocer como una nueva aplicación de su producto generaría daños.

Scherer plantea que, para el caso de producto defectuoso, el productor de IA certificado debe juzgarse con culpa, mientras que el no certificado se le imponga responsabilidad objetiva. Esto mediante la creación de una agencia gubernamental flexible que cumpla tareas de policía administrativa ${ }^{121}$.

5. La atribución por culpa coexistirá con la responsabilidad objetiva. Se adopta un modelo de deberes reforzados en donde se exigirá al operador directo; escoger, mantener y monitorear el sistema idóneo para la actividad que realice. También se valora la impericia en la manipulación o la negligencia en la elección o mantenimiento del sistema, ie. Actualizaciones, capacitación, seguimiento de instrucciones. El operador indirecto o productor, conserva deberes de seguridad, información, capacitación, comercialización y mantenimiento del robot.

Se plantea la necesidad de invertir la carga probatoria cuando las características lo exijan. Principalmente, por los costos de la obtención de la prueba. Esta asimetría puede derivar de: a. Demostrar el deber de conducta; b. La prueba del hecho ilícito; c. La explicación técnica de cómo data generó daño y en general, cuando exista una carga desproporcionada a partir de los rasgos de la IA.

Para el caso colombiano es además recomendable la definición de los términos jurídicos propios de este tipo de contratos, así como su delimitación objetiva más allá de las genéricas normas del EC, donde con la palabra "garantía" pretende compilar las particularidades de todos los productos sin reglamentación especial ${ }^{122}$ ie. ¿Qué es un bien digital? ¿Qué es el internet de las cosas en un contexto de consumo? ¿Cómo se negocia con datos? ${ }^{123}$ ¿Cuáles

Comercio (2019). Resolución Por La Cual Se Imparte Una Orden Administrativa (24 Enero). [Resolución 1321]" (2019). Por la cual se exige a Facebook Corp. una serie de medidas para proteger los datos de los usuarios nacionales.

121 "Regulating Artificial Intelligence Systems: Risks, Challenges, Competencies, and Strategies".

122 Carlos Germán CaYcedo, "Principios e Instituciones Del Derecho de Protección Del Consumidor En Colombia. Lineamientos Del Sistema Legal de Protección a Consumidores y Usuarios En Colombia, Conforme Con La Doctrina Constitucional y de Casación Civil"., in Perspectivas Del Derecho de Consumo, ed. Carmen Ligia Valderrama, 1st ed. (Bogotá D.C.: Editorial Universidad Externado, 2013), 159-226.

123 Herbert ZeCH, "A Legal Framework for a Data Economy in the European Digital Single 
son los deberes de seguridad? Ya es suficiente con la opacidad característica de la IA para sumarle omisiones legislativas por políticas anacrónicas de entornos digitales ya superados como el de la norma sobre mensaje de datos de 1999.

Asimismo, ha de plantearse la necesidad de instruir a los funcionarios judiciales de las tecnologías emergentes. Se justifica, por ejemplo, el reconocimiento de modelos regulatorios tecnificados como el de Buiten que propone etapas para evaluar fallas de la máquina ${ }^{124}$. También resulta interesante el planteamiento de Abbott sobre los deberes de utilización de robots cuando resulte razonable a partir de la relación costo-beneficio en seguridad y donde la máquina sea la nueva medida de diligencia ${ }^{125}$.

6. Este planteamiento de estándar de diligencia, va de la mano con la política para imponer una responsabilidad vicaria cuando se utilice IA en procesos donde un humano se sustituye. Por el principio de equivalencia funcional se pretende superar la incoherencia de tratar diferente a la máquina y al humano auxiliar. El riesgo creado por el robot puede generar responsabilidad objetiva o ser comparado con una persona o máquina media, según la tecnología amerite considerarse el estándar.

7. Como deber adicional la inclusión de logging by design, ie. Medios de información sobre la operación cuando necesario para determinar si un riesgo de daño se concretó. Esto, siempre que sea apropiado para el fin pretendido; proporcional en costos o medios de ejecución y respete derechos fundamentales. Su incumplimiento genera la presunción del hecho que su implementación efectiva hubiese probado.

Aquí, debió plantearse el deber de los productores de revelar el código de programación como forma de evitar la opacidad característica, siempre guardando un equilibrio con la propiedad intelectual del demandado. Se piensa además en la posibilidad de imponer tributos a empresas que promuevan esa falta de claridad y con este dinero crear fondos de compensación ${ }^{126}$.

Ese deber de documentación parece uno de los más importantes, el peligro radica en el uso que de esa información se haga. En Colombia no existe un sistema robusto de protección de datos como medio principal para el control, no solo de la causa de los daños, sino del uso que de ellos se hace en la práctica. Esta debilidad estructural es una de las principales deficiencias del sistema colombiano y debe ser subsanada lo antes posible si se pretende implementar un mercado digital.

Market: Rights to Use Data", Journal of Intellectual Property Law \& Practice 11, n. 6 (2016): 460-70, https://doi.org/10.1093/jiplp/jpw049.

124 "Towards Intelligent Regulation of Artificial Intelligence".

125 "The Reasonable Computer: Disrupting the Paradigm of Tort Liability"; "The Artificial Inventor Project."

126 SCHERER, "Regulating Artificial Intelligence Systems: Risks, Challenges, Competencies, and Strategies," 374. 
8. Si la actuación imprudente del demandado requiere la violación de un estándar de cuidado, las normas de seguridad constituyen ese parámetro. Tanto la Directiva 85/374/CEE ${ }^{127}$ como la Liability Act ${ }^{128}$ y el Restatement Third of Torts $^{129}$ del derecho norteamericano, definen que, a falta de norma, siempre existe una razonable expectativa de seguridad. En caso de su omisión o incumplimiento, se invertirá la carga probatoria de la causalidad, defecto o culpa. Como ya se había dicho, falta plantear que deberes de seguridad se exigen.

9. Frente a la causalidad y atendiendo a las dificultades técnicas presentadas, se ha definido que ciertos indicios deben permitir configurar la fuente del daño. Por ejemplo, la inferencia razonable que la IA causó o contribuyó con el daño; el riesgo de un defecto conocido ${ }^{130}$; la difusa trazabilidad o inteligibilidad de la información que pudo contribuir con la causa $a_{i}$ la accesibilidad y claridad de los datos recogidos y el tipo e intensidad del daño causado, serán factores para tener en cuenta para matizar la carga de la prueba de la causalidad en favor de la víctima. Estas morigeraciones probatorias se acogen en otros entornos como el de la prestación de servicios sanitarios con la res ipsa loquitur anglosajona, la Ancheinsbeweis del derecho alemán y la Faute Virtuelle francesa ${ }^{131}$.

10. Se indica que en el elemento daño es menor el impacto de las tecnologías emergentes. Así formula reglas indemnizatorias cuando por contrato, lesión a propiedad que contenga información, violación de normas o dolo, se destruya data de propiedad del usuario. Se pretende proteger la moderna propiedad digital, no solo tangible sino intangible, ie. Nubes de almacenamiento, etc. Esta propiedad se ha convertido en el principal activo de algunas empresas.

En el reporte anual ante la Comisión de Bolsa y Valores de los Estados Unidos, la compañía Microsoft manifestó su intención de ampliar su oferta a través de aplicaciones y dispositivos que integraran IA. Su principal preocupación: los datos podrían contener información sesgada y vulnerable a ataques, con influencia en las decisiones, predicciones y análisis de sus resultados y con directa incidencia en el riesgo reputacional de la empresa ${ }^{132}$.

127 Sobre productos defectuosos en su artículo 7.

128 American Congress, "H.R.1676-Uniform Product Liability Act" (1979), https://www. congress.gov/bill/96th-congress/house-bill/1676.

129 Section 402 -a The American Law Institute, "Restatement of the Law Third. Torts. Liability for Physical and Emotional Harm".

130 Tribunal de Justicia de la Unión Europea (TJUE), "Sentencia Del TJUE, 05.03.2015, ECLI:EU:C:2015:148, Asuntos Acumulados C-503/13 y C-504/13 (Boston Scientific Medizintech-Nik GmbH c. AOK Sachsen-Anhalt).," 2015.

131 Julio AlBI, "La Carga De La Prueba En Los Procedimientos De Responsabilidad Sanitaria", Revista Cesco de Derecho Del Consumo, n. ${ }^{\circ} 8$ (2013): 259-73, www.revista.uclm.es.

132 EeuU Microsoft Corp., "Microsoft Annual Report to United States Securities and Exchanged Commission" (Washington, 2019), https://www.sec.gov/Archives/edgar/ data/789019/000156459018019062/msft-10k_20180630.htm. 
11. Finalmente, el GENTRC establece la necesidad de imponer, en caso de actividades que frecuentemente causen daños, seguros obligatorios o fondos de compensación. Nada más lejos de la realidad colombiana.

\section{CONCLUSIONES}

Como sistemas de autoaprendizaje, la IA se estructura con algoritmos que le permiten aprender y decidir un resultado. Por ello se comparan con el ser humano, con su inteligencia. Esto lleva a que el hecho de la máquina sea valorado como el acto personal y consecuencialmente juzgado por igual. Cuando el automatismo y la ciencia computacional invaden todos los aspectos de la vida, inicia el proceso de identificación legislativo.

En el derecho de daños sus características de opacidad, complejidad, vulnerabilidad, data- estructura, autonomía, impredecibilidad y carácter abierto permean la política legislativa. En este escrito decidí agruparlas por rasgos comunes por considerar que algunas de ellas producen otras, así, la complejidad emana de su estructura de datos.

Al agruparlas se puso de presente la proyección que estos elementos tienen en el derecho de daños. Se deja claro que no es necesario reescribir el derecho, pero sí adecuar la estructura de la responsabilidad en ciertas situaciones.

La IA presenta retos al sistema tradicional del derecho de daños en todos sus elementos. Su principal influencia radica en el factor de atribución a partir de considerar si aplica una responsabilidad con o sin culpa.

Se concluye que es necesario pensar en la imposición de responsabilidad objetiva al usuario, propietario, productor o comercializador debido a la peligrosidad del producto, el beneficio obtenido y el control ejercido. En el primer caso se tiene en cuenta el entorno de operación y la previsibilidad del riesgo creado. El operador, según su rol, puede ser directo o indirecto.

La responsabilidad por producto defectuoso opera frente a una falla en el sistema, tanto de cosas tangibles como intangibles. Se puso de presente la incongruencia de esta política con instrumentos regulatorios vigentes. Se relacionó la decisión de excluir el riesgo en el desarrollo como causal eximente de responsabilidad indicando la necesidad en Colombia de aclarar legislativamente su aplicación en IA.

Además, se relacionó la obligación de brindar seguridad y mejoras del sistema. En este punto se planteó la preocupación por inexistencia de normas de seguridad en Colombia, así como la inocua normativa tecnológica que permita abordar contractualmente la imposición de estos deberes a los productores.

Igualmente, quienes produzcan, comercialicen, adquieran u operen IA, deben tener en cuenta obligaciones especiales derivadas de su rol. Entre otras, la capacitación, información, mantenimiento o actualización del sistema. El incumplimiento de ellos es constitutivo de culpa y servirá de fundamento para 
atribuir responsabilidad por daños. Indiqué que en el derecho colombiano esos deberes reclaman atención legislativa. No es suficiente imponer deberes de calidad, sin definir los requisitos de una prestación de base tecnológica.

Ha de tenerse cuidado, sobre todo en el entorno judicial colombiano, de que la imposición de deberes lleve a que no exista un límite claro en la responsabilidad objetiva y la objetivación de la culpa. Si los tribunales llegan a considerar que el uso de toda IA es actividad peligrosa o que deberes como los propuestos son absolutos, la tecnología llegará a prohibirse jurisprudencialmente ${ }^{133}$.

En punto de la causalidad, se plantea la imposición de deberes de documentación a los productores de IA con el fin de determinar -si necesario y adecuado-, de donde provino el daño. El incumplimiento a este deber hace presumir el hecho que debió conocerse. Esto pretende alivianar la carga de la víctima que por costos y dificultad probatoria llegare a desistir de la reclamación. La presunción de causalidad también opera si dada la opacidad o complejidad del sistema, se dificulta demostrar al dañado el origen del perjuicio.

Estas morigeraciones probatorias se justifican además cuando la dificultad derive de la demostración del defecto, del daño o del factor de atribución según el caso. Las condiciones de la tecnología emergente lo justificarán según cada caso.

Además, se relacionó la conveniencia de seguros obligatorios o sistemas de compensación que distribuyan los deberes indemnizatorios en casos en que la frecuencia y gravedad de los daños así lo reclame.

Ha de finalizarse indicando que el mercado colombiano exige plena atención a una realidad que no puede obviarse sin las graves consecuencias que en productividad, crecimiento, celeridad, efectividad y proyección económica se vienen asumiendo. El Gobierno Nacional advirtió esta falencia al pretender cumplir directivas de la OCDE con un plan de acción que en recursos y acciones resultará insuficiente teniendo en cuenta la creciente inversión internacional en desarrollo y explotación de nuevas tecnologías. Según el ITU de la ONU, a 2030 el impacto de la nueva tecnología alcanzará los \$6 trillones de dólares. La carrera ha iniciado y quien no haga la tarea pagará el precio ${ }^{134}$.

\section{REFERENCIAS BIBLIOGRÁFICAS}

AвbOTt, RYAN. "The Artificial Inventor Project." WIPO Magazine, 2019. https://www. wipo.int/wipo_magazine/en/2019/06/article_0002.html.

133 Martin Ebers, "La Utilización de Agentes Electrónicos Inteligentes En El Tráfico Jurídico: ¿Necesitamos Reglas Especiales En El Derecho de La Responsabilidad Civil?", Indret: Revista Para El Análisis Del Derecho, n. 3 (2016): 3.

134 "Assessing the Economic Impact of Artificial Intelligence", 18. 
- — - "The Reasonable Computer: Disrupting the Paradigm of Tort Liability." George Washington Law Review 86, n. ${ }^{\circ} 1$ (2018): 1-45. https://doi.org/10.2139/ ssrn. 2877380 .

Albi, Julio. "La Carga De La Prueba En Los Procedimientos De Responsabilidad Sanitaria". Revista Cesco de Derecho Del Consumo, n. ${ }^{\circ} 8$ (2013): 259-73. www.revista. uclm.es.

American Congress. H.R.1676-Uniform Product Liability Act (1979). https://www. congress.gov/bill/96th-congress/house-bill/1676.

——_. "Regulation of Artificial Intelligence in Selected Jurisdictions", 2019. http:// www.law.gov.

Ángel YÁGueZ, Ricardo De. "Actuación Dañosa de Los Grupos". Revista Jurídica de Cataluña, n. ${ }^{\circ} 4$ (1997): 63-91.

Basau, TAnya. "The Robot Does the Hard Work. Can You Still Attain Enlightenment?". MIT Technology Review, 2020. https://www.technologyreview. $\mathrm{com} / \mathrm{s} / 615267 /$ the-robot-does-the-hard-work-can-you-still-attain-enlightenment/.

BBC. "5 Claves Para Entender El Escándalo de Cambridge Analytica Que Hizo Que Facebook Perdiera US\$37.000 Millones En Un Día-bbc News Mundo." BBC News, 2018. https://www.bbc.com/mundo/noticias-43472797.

__—_. "Tay, La Robot Racista y Xenófoba de Microsoft-BBC News Mundo." BвC, 2016. https://www.bbc.com/mundo/noticias/2016/03/160325_tecnologia_microsoft_tay_bot_adolescente_inteligencia_artificial_racista_xenofoba_lb.

BвC Mundo Tecnología. "Google Pide Perdón Por Confundir a Una Pareja Negra Con Gorilas". BBC, 2015. https://www.bbc.com/mundo/noticias/2015/07/150702_tecnologia_google_perdon_confundir_afroamericanos_gorilas_lv.

BeAle, Hugh. "The Role for European Contract Law." In Uniform Rules for European Contract Law? A Critical Assessment, edited by Francisco Elizalde de, 1. ${ }^{a}$ ed., 9-36. Oxford: Hart Publishing, 2018.

Buiten, MiRIAM C. "Towards Intelligent Regulation of Artificial Intelligence". European Journal of Risk Regulation 10, n. ${ }^{\circ} 1$ (2019): 41-59. https://doi.org/10.1017/ err.2019.8.

Burrell, JennA. "How the Machine 'Thinks': Understanding Opacity in Machine Learning Algorithms". Big Data and Society 3, n. ${ }^{\circ} 1$ (2016): 1-12. https://doi. org/10.1177/2053951715622512.

Burton, Simon, Ibrahim Habli, Tom Lawton, John McDermid, Phillip Morgan, and Zoe Porter. "Mind the Gaps: Assuring the Safety of Autonomous Systems 
from an Engineering, Ethical, and Legal Perspective". Artificial Intelligence 279 (2020). https://doi.org/10.1016/j.artint.2019.103201.

Business insider. "Artificial Intelligence Is Changing These 9 Industries". Business Insider, 2017. https://www.businessinsider.com/sc/artificial-intelligencecompanies? IR=T.

Calo, Ryan. "Robotics and the Lessons of Cyberlaw". California Law Review, n. 103 (2015): 513-63.

"Robots in American Law," 2016. http://ssrn.com/abstract=2737598.

Cámara lapuente, Sergio. "La Nueva Protección Del Consumidor de Contenidos Digitales Tras La Ley 3/2014, de 27 de Marzo." Revista CESCO de Derecho de Consumo, n. ${ }^{\circ} 11$ (2014): 79-167.

Cameron, James. The Terminator. USA, 1984.

Caycedo, Carlos Germán. "Principios e Instituciones Del Derecho de Protección Del Consumidor En Colombia. Lineamientos Del Sistema Legal de Protección a Consumidores y Usuarios En Colombia, Conforme Con La Doctrina Constitucional y de Casación Civil." In Perspectivas Del Derecho de Consumo, edited by Carmen Ligia Valderrama, 1. ${ }^{\text {a }}$ d., 159-226. Bogotá D.C.: Universidad Externado de Colombia, 2013.

Columbus, Louis. "10 Charts That Will Change Your Perspective Of AI In Security". Forbes, 2019. https://www.forbes.com/sites/louiscolumbus/2019/11/04/10-chartsthat-will-change-your-perspective-of-ai-in-security/\#311de57d68b7.

Comisión de Regulación de Comunicaciones, Colombia. "Resumen Recomendaciones Normativas y Regulatorias Para Promocionar Los Contenidos y Aplicaciones y El Internet de Las Cosas". Bogotá, 2016. https://www.crcom.gov.co/recursos_user/2016/Actividades_regulatorias/PCA _IoT/Informe_6_PCA _IoT.pdf.

Comisión Europea. "Una Agenda Digital Para Europa," 2010.

Comisión Europea, UE. "Comisión Europea (2018). Documento de Trabajo de La Comisión Europea En Responsabilidad Por Tecnologías Digitales Emergentes. (25 de Abril) SWD (2018) 137 Final." Bruselas, 2018. https://doi.org/10.1017/ СВО9781107415324.004.

. "Commission Staff Working Document. Liability for Emerging Digital Technologies Accompanying the Document Communication from the Commission to the European Parliament, the European Council, the Council, the European Economic and Social Committee and the Co", 2018. https://eur-lex.europa.eu/ legal-content/EN/TXT/PDF/?uri=CELEX:52018SC0137\&from=en. 
- — - "Register of Commission Expert Groups and Other Similar Entities", 2018. https://ec.europa.eu/transparency/regexpert/index.cfm?do=groupDetail. groupDetail\&groupID $=3592$.

Congreso de la República de Colombia, Colombia. Congreso de Colombia. (2011). Por medio de la cual se expide el estatuto del consumidor y se dictan otras disposiciones. [Ley 1480 de 2011] ctubre 12. D.O.48.220 (2011).

Consejo Europeo, UE. Consejo Europeo (1985). Relativa a la aproximación de las disposiciones legales, reglamentarias y administrativas de los Estados miembros en materia de responsabilidad en daños causados por productos defectuosos. (25 de julio) [Directiva 85/374/CEE]. D.O: (1985).

Consejo Nacional de Política Económica y Social, CONPES. "Documento CONPES 3975 Del 8 de Noviembre de 2019". Bogotá D.C., 2019.

Corte Suprema de Justicia de Colombia. "C.S.J, Sala Civil (24 de Agosto de 2009) [M.P. William Namén Vargas]." Bogotá D.C., 2009.

__— _ "C.S.J, Sala Civil. (Marzo 14 de 1955)[M.P.Fernando Gómez Posse] G.J. XXIX, p. 740." Bogotá D.C., 1955.

Davies, Alex. "This Vehicle Has No Side-View Mirrors-and It's Legal." Wired, 2020. https://www.wired.com/story/vehicle-no-side-view-mirrors-legal/.

DEAN, WEST. "Farming-Using Artificial Intelligence, Agricultural Robots Are on the Rise." The Economist, 2020. https://www.economist.com/science-and-technology/2020/02/06/using-artificial-intelligence-agricultural-robots-are-on-the-rise.

Díez-PICAZO, Luis. Fundamentos de Derecho Civil Patrimonial V. La Responsabilidad Civil Extracontractual. 1st ed. Navarra: Civitas, 2011.

Díez Picazo, Luis, and Antonio Gullón. Sistema de Derecho Civil. Vol. II. 6. ${ }^{a}$ ed. Madrid: Tecnos, 1992.

Diresta, ReneE. "A New Law Makes Bots Identify Themselves-That's the Problem I WIRED." Wired, 2019. https://www.wired.com/story/law-makes-bots-identifythemselves/.

Ebers, MARTin. "La Utilización de Agentes Electrónicos Inteligentes En El Tráfico Jurídico : ¿Necesitamos Reglas Especiales En El Derecho de La Responsabilidad Civil?" Indret: Revista Para El Análisis Del Derecho, n. ${ }^{\circ} 3$ (2016): 3.

European Group on Tort Law. Principios de Derecho Europeo de La Responsabilidad Civil. Principios de Derecho Europeo de La Responsabilidad Civil. Texto y Comentario. Traducción Española a Cargo de La Red Española de Derecho Privado y Comparado redpec. 1. a ed. Navarra: Thomson Aranzadi, 2008. 
European Law Institute. "Statement of the European Law Institute On the European Commission's Proposed Directive on the Supply of Digital Content to Consumers," 2015.

Expert Group on Liability and New Technologies. "Liability for Artificial Intelligence Report from the Expert Group on Liability and New Technologies-New Technologies Formation," 2019. https://doi.org/10.2838/25362.

Fomperosa, Mariana. "CCómo La IA de Facebook Pudo Crear Su Propio Lenguaje?" Milenio, 2018. https://www.milenio.com/estilo/como-la-ia-de-facebook-pudocrear-su-propio-lenguaje.

Galindo, Juan Carlos. "Así Se Hizo El Primer Spot de Publicidad Creado Con Inteligencia Artificial". muyinteresante.es. Accessed February 23, 2020. https:// www.muyinteresante.es/tecnologia/inteligencia-artificial/articulo/asi-se-hizoel-primer-spot-de-publicidad-creado-con-inteligencia-artificial-461542818130.

García Vicente, José Ramón. "La Contratación Con Consumidores". In Tratado de Contratos, Tomo II. 2 Edición, edited by Rodrigo Bercovitz, 1. a ed., 1629-1790. Valencia: Tirant lo Blanch, 2013.

International Telecomunication Union. "ITU: Committed to Connecting the World", 2019. https://www.itu.int/en/Pages/default.aspx.

ITU. "Assessing the Economic Impact of Artificial Intelligence". ITU Trends 3, n. 1 (2018): 5170-79. https://www.itu.int/dms_pub/itu-s/opb/gen/S-GEN-ISSUEPAPER2018-1-PDF-E.pdf.

KOWERT, W. "The Foreseeability of Human-Artificial Intelligence Interactions". Texas Law Review 96, n. ${ }^{\circ} 1$ (2017): p181-204. http://scroll.lib.westfield.ma.edu:2090/ ehost/detail/detail?vid=3\&sid=2e573118-5b03-4fd6-9c4e-e61699bd5225\% 40sessionmgr4009\&bdata $=$ JnNpdGU9ZWhvc3QtbG12ZQ\%3D\%3D\#db $=$ aph\& $\mathrm{AN}=126913534$.

Kubrick, StAnley. 2001: Una Odisea En El Espacio. USA, 1968.

LAMB, JHON. "Discriminating Algorithms: 5 Times AI Showed Prejudice". NewScientist, 2018. https://www.newscientist.com/article/2166207-discriminatingalgorithms-5-times-ai-showed-prejudice/.

Lemley, Mark A., and Bryan Casey. "You Might Be a Robot". SSRN Electronic Journal, 2019, 1-55. https://doi.org/10.2139/ssrn.3327602.

MARÍn, RAFAEL. "Ingeniería Inversa: Herramientas a Utilizar Para Llevarla a Cabo". Accessed March 23, 2020. https://revistadigital.inesem.es/informatica-y-tics/ ingenieria-inversa/. 
Mazeaud, H. L. J. Lecciones de Derecho Civil. Parte Tercera. Vol. IV. Los Principales Contratos (Continuación). Edited by Luis Alcalá-Zamora y Castillo. 1st ed. Buenos Aires: Ediciones Jurídicas Europa-América, 1974.

Microsoft Corp., EEUU. "Microsoft Annual Report to United States Securities and Exchanged Commission". Washington, 2019. https://www.sec.gov/Archives/ edgar/data/789019/000156459018019062/msft-10k_20180630.htm.

Ministerio de las tecnologías de la información y las comunicaciones, Colombia "MinTIC Ya Está Implementando Las Recomendaciones de La OCDE Para La Trasformación Digital". Mintic.gov.co, 2019. https://www.mintic.gov.co/portal/ inicio/Sala-de-Prensa/Noticias/106833:MinTIC-ya-esta-implementando-lasrecomendaciones-de-la-OCDE-para-la-trasformacion-digital.

Ministerio de las tecnologías de la información y las comunicaciones, Colombia, and ССВ Cámara de Comercio de Bogotá. "Observatorio de Economía Digital En Colombia". Bogotá, 2017. https://www.mintic.gov.co/portal/604/articles-61929_recurso_4.pdf.

Musk, Elon. "Master Plan, Part Deux | Tesla". Tesla.com, 2016. https://www.tesla. $\mathrm{com} / \mathrm{blog} / \mathrm{master}$-plan-part-deux.

Naveen, Joshie. "How AI Can Transform The Transportation Industry". Forbes, 2019. https://www.forbes.com/sites/cognitiveworld/2019/07/26/how-ai-cantransform-the-transportation-industry/\#2eb20ce34964.

Pantaleón, Fernando. "Causalidad e Imputación Objetiva: Criterios de Imputación". In Centenario Del Código Civil (1889-1989), t. II, edited by Editorial Centro de Estudios Ramón Areces, 1561-92. Madrid: Centro de estudios Ramón Areces, 1990.

Papayannis, Diego. "Veinte Años de Riesgos y Daños. Una Propuesta Arriesgada y Poco Dañosa". In Derecho de Daños, Principios Morales y Justicia Social, edited by Diego Papayannis, 1. a ed., 13-37. Barcelona: Marcial Pons, 2013.

Parlamento Unión Europea. "Política Industrial Global Europea En Materia de Inteligencia Artificial y Robótica". 12-02-2019, 2019. http://www.europarl.europa. eu/doceo/document/TA-8-2019-0081_ES.html? redirect.

Parlamento y Consejo Europeo, UE. Parlamento y Consejo Europeo. (20 de mayo). Directiva (UE) 2019/771 relativa a determinados aspectos de los contratos de compraventa de bienes, por la que se modifican el Reglamento (CE) n. ${ }^{\circ}$ 2017/2394 y la Directiva 2009/22/CE y se deroga la Directiva 199 (2019).

Parlamento y Consejo Europeo. (20 de mayo) Directiva (UE) 2019/770 relativa a determinados aspectos de los contratos de suministro de contenidos y servicios digitales. D.O: 22 de mayo de 2019. (2019). 
_-_ Parlamento y Consejo Europeo. [Mayo 25 de 1999]. Sobre determinados aspectos de la venta y las garantías de los bienes de consumo. (Directiva 1999/44/ CE). D.O: L.171/12 (Julio 7/99) (1999).

Real Academia de la Lengua Española, España. "Definición de Inteligencia". Diccionario de la RAE, 2020. https://dle.rae.es/inteligencia\#2DxmhCT.

Robotics Openletter. "Robotics Openletter I Open Letter to the European Commission", 2017. http://www.robotics-openletter.eu/.

Rodriguez de las Heras, Teresa. "Legal Challenges of Artificial Intelligence: Modelling the Disruptive Features of Emerging Technologies and Assessing Their Possible Legal Impact". Uniform Law Review 24, n. ${ }^{\circ} 2$ (2019): 302-14.

Rodríguez De Las Heras, Teresa. "Digital Technology-Based Solutions for Enhanced Effectiveness of Secured Transactions Law: The Road to Perfection?" Law and Contemporary Problems 81, n. ${ }^{\circ} 1$ (2018): $21-44$.

RuSHE, DOMINIC. "Tesla Driver Who Died in 'autopilot' Crash Was Playing on Phone, Inquiry Finds | Technology |". The Guardian, 2020. https://www.theguardian. com/technology/2020/feb/25/tesla-driver-autopilot-crash.

SCHERER, MATTHEW U. "Regulating Artificial Intelligence Systems: Risks, Challenges, Competencies, and Strategies". SSRN Electronic Journal 29, n. 2 (2015). https:// doi.org/10.2139/ssrn.2609777.

Scholz, Stephanie. "AI in Society-For Artificial Intelligence to Thrive, It Must Explain Itself". The Economist, 2018. https:/www.economist.com/science-andtechnology/2018/02/15/for-artificial-intelligence-to-thrive-it-must-explain-itself.

SPIER, J. Unification of Tort Law: Liability for Damages Caused by Others. Edited by European Center of Tort and Insurance Law (ECTIL). 1. ${ }^{a}$ ed. Vienna: Kluwer Law, 2003.

Study Group on a European Civil Code, UE. "Principles, Definitions and Model Rules of European Private Law", 2007.

Superintendencia de Industria y Comercio, Colombia. Superintendencia de Industria y Comercio (2019). Resolución por la cual se imparte una orden administrativa (24 enero). [Resolución 1321] (2019).

Tamayo, Javier. Responsabilidad Por Productos Defectuosos. Primera. Bogotá D.C.: Legis, 2016.

Tratado de La Responsabilidad Civil. Tomo I. 2. ${ }^{a}$ ed. Bogotá D.C.: Legis, 2013.

The American Law Institute. "Restatement of the Law Third. Torts. Liability for Physical and Emotional Harm". Philadelphia, 2005. 
Tribunal de Justicia de la Unión Europea (TJUE). "Sentencia Del STJUE (Gran Sala) Del 21.12.2011, Caso C-495/10 Consulta Elevada Por Conseil d'État (Francia)", 2011.

—_—_. "Sentencia Del STuUE Del 24.3.2002, Caso C-183/00 Partes: González Sanchez vs. Medicina Asturiana", 2002.

"Sentencia Del TJUe, 05.03.2015, ECLI:EU:C:2015:148, Asuntos Acumulados C-503/13 y C-504/13 (Boston Scientific Medizintech-Nik GmbH c. AOK Sachsen-Anhalt)"., 2015.

Turing, Alan. "Computing Machinery and Intelligence". Mind, n. ${ }^{\circ} 49$ (1950): 433 60. https://doi.org/10.5603/ARM.a2017.0044.

UNICRI. "Artificial Intelligence and Robotics". Accessed March 16, 2020. http://www. unicri.it/topics/ai_robotics/.

US News. "Best Artificial Intelligence Programs-Top Science Schools-US News Rankings". US News, 2018. https://www.usnews.com/best-graduate-schools/ top-science-schools/artificial-intelligence-rankings.

Vida, José. "Los Retos De la Regulación De La Inteligencia Artificial: Algunas Aportaciones Desde La Perspectiva EuropeA". In Sociedad Digital y Derecho, edited by Tomás De la Quadra-Salcedo, 1. ${ }^{a}$ ed., 203-24. Barcelona: BOE, 2018.

VladeCK, DAVID C. "Machines without Principals: Liability Rules and Artificial Intelligence". Washington Law Review 89, n. ${ }^{\circ} 1$ (2014): 117-50.

Wikipedia. "Historia de La Inteligencia Artificial-Wikipedia, La Enciclopedia Libre." Wikipedia, 2020. https://es.wikipedia.org/wiki/Historia_de_la_inteligencia_artificial.

"Sistema Quirúrgico Da Vinci-Wikipedia, La Enciclopedia Libre." Wikipedia, 2019. https://es.wikipedia.org/wiki/Sistema_quirúrgico_Da_Vinci.

YAVAR BATHAEE. "The Artificial Intelligence Black Box and the Failure of Intent and Causation". Harvard Journal of Law \& Tecbnology 31, n. ${ }^{\circ}$ (2018): 890-938. https:// www.theverge.com/.

ZeCH, Herbert. "A Legal Framework for a Data Economy in the European Digital Single Market: Rights to Use Data." Journal of Intellectual Property Law \& Practice 11, n. ${ }^{\circ} 6$ (2016): 460-70. https://doi.org/10.1093/jiplp/jpw049. 